\title{
Recent advances in understanding the Arctic climate system state and change from a sea ice perspective: a review
}

\author{
R. Döscher ${ }^{1}$, T. Vihma ${ }^{2}$, and E. Maksimovich ${ }^{3}$ \\ ${ }^{1}$ Swedish Meteorological and Hydrological Institute (SMHI), Norrköping, Sweden \\ ${ }^{2}$ Finnish Meteorological Institute (FMI), Helsinki, Finland \\ ${ }^{3}$ Ifremer, Laboratory of Oceanography from Space, Brest, France \\ Correspondence to: R. Döscher (ralf.doescher@smhi.se)
}

Received: 16 January 2014 - Published in Atmos. Chem. Phys. Discuss.: 30 April 2014

Revised: 10 October 2014 - Accepted: 10 November 2014 - Published: 19 December 2014

\begin{abstract}
Sea ice is the central component and most sensitive indicator of the Arctic climate system. Both the depletion and areal decline of the Arctic sea ice cover, observed since the 1970s, have accelerated since the millennium. While the relationship of global warming to sea ice reduction is evident and underpinned statistically, it is the connecting mechanisms that are explored in detail in this review.

Sea ice erodes both from the top and the bottom. Atmospheric, oceanic and sea ice processes interact in nonlinear ways on various scales. Feedback mechanisms lead to an Arctic amplification of the global warming system: the amplification is both supported by the ice depletion and, at the same time, accelerates ice reduction. Knowledge of the mechanisms of sea ice decline grew during the 1990s and deepened when the acceleration became clear in the early 2000s. Record minimum summer sea ice extents in 2002, 2005, 2007 and 2012 provide additional information on the mechanisms.

This article reviews recent progress in understanding the sea ice decline. Processes are revisited from atmospheric, oceanic and sea ice perspectives. There is strong evidence that decisive atmospheric changes are the major driver of sea ice change. Feedbacks due to reduced ice concentration, surface albedo, and ice thickness allow for additional local atmospheric and oceanic influences and self-supporting feedbacks. Large-scale ocean influences on Arctic Ocean hydrology and circulation are highly evident. Northward heat fluxes in the ocean are clearly impacting the ice margins, especially in the Atlantic sector of the Arctic. There is little indication of a direct and decisive influence of the warming ocean on
\end{abstract}

the overall sea ice cover, due to an isolating layer of cold and fresh water underneath the sea ice.

\section{Introduction}

Sea ice is the primary indicator of the state of climate in the central Arctic. Its sensitivity incorporates changes in response to global scale climate forcing, as well as climate variability internal to the global climate system and internal to the Arctic. Sea ice is affected by thermal, radiative and dynamical changes of both Arctic atmosphere and ocean. Feedbacks from both the atmosphere and ocean modify the nature of the sea ice response.

Sea ice has distinctly evolved since satellite observations began in 1979. These measurements have enabled unprecedented accuracy in monitoring sea ice concentration and extent, including interannual variability. A long-term decline of summer sea ice extent of $-12.9 \%$ per decade is evident from the start of the record (Meier et al., 2012). After the year 2000, the decadal trend in summer sea ice extent loss has strengthened and stands out as a period of distinct and persistent decline.

Prior to the satellite era (1979), knowledge and observation of the sea ice extent was either local or episodic. Reconstructions based on a limited number of local observations have been carried out, resulting for example in the HadISST2 data set (Rayner et al., 2006). Inconsistencies in the transition between traditional observations and the satellite record led to a recent correction of the sea ice extent time series before 1979 (Meier et al., 2012, 2013), which brought to light a 
large interannual variability superimposed on a rather stable summer sea ice extent from the 1950s through to the 1970s. The overall summer sea ice extent trend for the 1953-2011 period is estimated at $-6.8 \%$ per decade.

Modern knowledge of large-scale sea ice thickness began with submarine surveys during the 1950s. Sonar measurements give a picture of thinning sea ice. Combining these with follow-up satellite retrievals from ICESat data (after 2003) gives an overall mean winter thickness decrease from $3.8 \mathrm{~m}$ in 1980 to $1.9 \mathrm{~m}$ in 2007-2008 (Kwok and Rothrock, 2009). The new generation CryoSat- 2 satellite (Laxon et al., 2013) has reconfirmed this ice loss tendency.

Prior to 1950, knowledge of the state of Arctic climate is poor. The so-called "early Arctic warming" - first observed during the 1930s, and which peaked during the 1940s - is clearly identifiable from atmospheric surface temperature anomalies from Arctic land stations (e.g. Johannessen et al., 2004). However, there is no known indication for the overall summer sea ice reduction. Reasons and mechanisms for the early Arctic warming are subject to debate. It has been shown that natural variability likely contributed to the warming (Wood and Overland, 2010; Bengtsson et al., 2004). Hypotheses relying on a dominant solar influence on the warm anomaly (e.g. Lean and Rind, 1998) could not be substantiated (Thejll and have Lassen, 2000). Considering the millennium timescale, Kaufman et al. (2009), provided an extensive palaeo-reconstruction of circumpolar land-based Arctic summer temperatures over the past 2000 years based on proxies such as lake sediments, pollen records, diatoms, and tree rings. Their study demonstrated that the recent Arctic warming is unprecedented during the last 2000 years.

As the globe as a whole has warmed during recent decades, the Arctic has done so more strongly than other regions. Such polar amplification of the global warming signal was first envisaged by Arrhenius (1896) and later recognized by Broecker (1975). Manabe and Wetherald (1975) attributed the high latitude amplification signal in one of the first coupled global climate models (GCMs) to what is known as ice-albedo feedback. They also noted a role of the geographically different vertical structure of warming for the amplification, corresponding to the lapse rate feedback (see Sect. 2.1). Recent research indicates a combination of various regional feedback mechanisms act in conjunction with circulation changes to cause both the observed and simulated Arctic amplification (Serreze and Barry, 2011; Pithan and Mauritsen, 2014). Arctic amplification both reflects and forces sea ice changes.

The summer extent record after 2000 has followed a trend of amplified decline, eventually leading to record summer minima in 2002, 2005, 2007 and 2012. These events are drastic illustrations of ongoing quantitative and qualitative changes; the 2007 event especially marked a threshold in human consciousness of recent Arctic sea ice history (Nilsson and Döscher, 2013). The impact of Arctic processes became more obvious. A transformation of the Arctic climate system towards a "new Arctic" was manifest through the increased fraction of young first year ice (Maslanik et al., 2011), thinner ice, a warmer ocean, and increased near-surface air temperatures. This "new Arctic" is expressing itself as a qualitative change noticeable not only by sea ice-related shifts, but also by enhanced meridional atmospheric circulation components (Sect. 4.1) and a warming of the Atlantic water layer in the mid-depth Arctic ocean, unprecedented in observed history (Spielhagen et al., 2011).

The detection of Arctic climate change in terms of atmospheric temperature has historically been difficult due to regionally strong natural variability, such as early Arctic warming with a subsequent temporal cooling. Under such conditions, detection of a long-term change signal or a trend requires a long observation time series in order to prove significance. Only recently has a significant multi-decadal trend been possible to detect (Min et al., 2008), although human influenced-sea ice loss could have been detected as early as 1992 if currently used statistical methods (i.e. optimal detection analysis) had been available.

Our ability to identify real changes in various aspects of the Arctic climate system increases when focusing on individual seasons. Anthropogenic signals have become detectable in colder seasons (Min et al., 2008). However, it is difficult to clearly attribute Arctic climate change to human influence based solely on observations (Overland and Wang, 2010). One strategy has therefore been to combine observation-based data and climate model data. A recent study, based on an up-to-date gridded data set of land surface temperatures and simulations from four coupled climate models (Gillet et al., 2008), concluded that the anthropogenic influence on Arctic temperature is detectable and distinguishable from the influence of natural forcing, i.e. it is statistically attributable to human greenhouse gas emissions. This conclusion and progress after previous studies was possible due to an updated gridded data set of land temperatures, allowing for more regional comparison with a model ensemble.

Given this background of detectable and anthropologically attributable Arctic climate change apparent in the sea ice cover, we find it useful to synthesize recent insights into the reasons for Arctic sea ice reduction and the underlying character of changes and the processes involved in the atmosphere and ocean. Recent reviews of the sea ice decrease (e.g. Stroeve et al., 2012 and Polyakov et al., 2012) specifically look at a range of important contributing components. Here we instead take a broader system-wide view of sea ice decline, taking the changing overall Arctic physical climate system into account.

Arctic sea ice change includes global scale impacts, as well as regionally changing interaction mechanisms and trends. We review existing peer-reviewed literature covering sea ice changes in combination with associated atmospheric and oceanic changes. Part of the reviewed work was carried out during the international polar year (IPY) and the European DAMOCLES project. Special attention is given to re- 
cent knowledge updates that shed new light on previously existing results. We focus on the large-scale state and changes in the Arctic climate system, affecting and interacting with the sea ice cover. (Recent advances in understanding smallscale physical processes were addressed in another DAMOCLES synthesis paper by Vihma et al. (2014).) For a discussion of the consequences and impacts of declining sea ice cover, see e.g. Meier et al. (2014): this introduction briefly summarizes the 20th century history of research advances concerning Arctic sea ice. Section 2 gives an overview of the Arctic climate system as an integral part of the global climate system. Section 3 reviews recent sea ice change, and is followed by Sect. 4 on the influence of the atmospheric changes and Sect. 5 on the impact of the ocean on sea ice change.

\section{The Arctic as part of the coupled climate system}

Climate change in the Arctic and on a global scale are intensely intertwined. The Arctic represents a heat sink with both oceanic and atmospheric heat flux convergence. Our understanding is challenged by a range of interacting processes, complicated by a strong interannual and decadal variability in the Arctic climate. The recent Arctic warming in conjunction with sea ice depletion can be seen as part of a regional expression of a global warming. Arctic warming is detectable (Min et al., 2008) and can be statistically attributed to a globally changed atmospheric radiation balance, due to increased atmospheric greenhouse gas concentrations (Gillet et al., 2008; Notz and Marotzke, 2012). The regional shaping and amplitude of the Arctic warming is governed by processes in the Arctic itself, in conjunction with feedbacks which act differently within and outside the Arctic.

\subsection{Arctic amplification}

The first climate model scenario simulations from the 1970s showed global warming was amplified in the Arctic (Manabe and Wetherald, 1975). Since then, an Arctic amplification of the global warming signal has been revealed in observations and shown to intensify (Johannessen et al., 2004). Arctic amplification is now considered an inherent characteristic of the global climate system (Serreze and Barry, 2011). Global scale warming triggers Arctic processes leading to a regionally amplified warming. The roles of retracting sea ice and snow coverage have been widely described (e.g. Maksimovich and Vihma, 2012). The basic sea ice-albedo feedback process begins in spring, when the surface albedo decreases due to snow metamorphosis and melt. The feedback strengthens as the melt exposes larger fractions of the ocean surface, and heat is more effectively absorbed by the ocean (Perovich et al., 2007b). This excess heat delays the start date of freezing, causing thinner winter ice and a corresponding preconditioning of the following summer's sea ice cover (Blanchard-Wrigglesworth et al., 2011). A corre- sponding process applies to the ice or snow surface under conditions of thinning and reducing multi year ice. Decreasing sea ice albedo during the melting phase leads to thinner ice, memorized into the following winter (Perovich and Polashenski, 2012; Notz, 2009). Direct positive feedbacks, in connection with reduction of ice concentration or thinning of ice, explain why the strongest observed, and projected future warming is located over ocean-sea ice boundaries (Screen and Simmonds, 2010b; Overland et al., 2011, Koenigk et al., 2011), with the strongest seasonal signature in autumn and winter.

In addition to the role of the sea ice-albedo feedback, understanding of the Arctic amplification has become more nuanced during recent years, involving contributions of cloud and water vapour feedback, temperature feedback, atmospheric circulation feedbacks and reduced mixing in the Arctic atmospheric boundary layer all modifying the direct effects of Arctic climate warming (Soden et al., 2008). In addition, the transport of heat into the Arctic by both the ocean (e.g. Polyakov et al., 2010) and atmosphere (e.g. Serreze et al., 2009) has been shown to play a role.

The temperature feedback is commonly defined as the response to a warming of the surface or the atmosphere by increased long-wave radiation by the fourth power of the temperature. The effect is measurable at the top of the atmosphere. Due to the generally colder temperatures in the Arctic, the increase of outgoing heat radiation in response to an equal temperature increase is less at Arctic latitudes, which potentially constitutes a contribution to the Arctic amplification.

The temperature feedback can be further refined and formally split into the Planck feedback, the contribution by a vertically homogeneous warming, and the lapse rate feedback. The latter, associated with the vertical structure of warming, builds on a reduced atmospheric lapse rate ("steepening") under the conditions of a global warming (Soden et al., 2008), leading to a greater warming in the upper troposphere than at the surface. The lapse rate in the vertical is affected by mixing, which in the tropics effectively conveys a surface warming signal to high altitudes that is radiated to space. This is generally a negative feedback cooling the surface. However, in the Arctic the vertical transfer of heat is prevented by a stably stratified atmosphere, transforming the regional lapse rate feedback from negative to positive, and contributing to the Arctic amplification.

Clouds and water vapour in the Arctic affect the regional radiation balance by blocking incoming short-wave solar radiation, effectively cooling the surface. At the same time, increased downward long-wave radiation has a warming effect on the surface temperature. In contrast to lower latitude clouds, Arctic clouds, and especially low Arctic clouds, are, on a yearly-average basis, found to warm the surface (Kay and L'Ecuyer, 2013; Intrieri et al., 2002). The net effect of Arctic clouds thus constitutes an amplified warming in response to increased cloudiness, i.e. a positive cloud feed- 
back. Various sources indicate that Arctic cloud cover has increased during recent decades (see Sect. 4.3)

The water vapour feedback refers to increased water vapour content in the atmosphere in response to a warming of the sea surface temperature. Water vapour acts as a greenhouse gas and thus the water vapour feedback is generally positive, independent of location. Langen et al. (2012) broke down the impacts of the different feedbacks of Arctic amplification with the help of an idealized climate model configuration, with the result that the water vapour feedback does not in itself lead to an Arctic amplification. It does however strengthen the local response to other amplified positive feedbacks in the Arctic. Existing contributions to the Arctic amplification, such as the ice-albedo feedback and the combined temperature feedback, generate increased Arctic surface temperatures, which in turn increase water vapour emissions with an associated atmospheric warming in the Arctic.

The cloud feedback contribution is potentially capable of explaining the Arctic amplification on its own, without the support of a sea ice-albedo feedback. This is indicated in model studies with sea ice-albedo feedback disabled by a fixed albedo (Langen and Alexeev, 2007; Graversen and Wang, 2009). Among the remaining mechanisms, the combined cloud feedback and the water vapour feedback (which does not in itself generate an amplification) play the leading roles. Similar to the lapse rate feedback, the effect is supported by a generally stable stratification without convective mixing in the Arctic atmospheric boundary layer, hindering vertical mixing of humidity and thus maintaining increased humidity at lower levels. A more complete summary of the mechanisms involved in the Arctic amplification are given by Serreze and Barry (2011), and Pithan and Mauritsen (2014).

Important insights come from the analyses of global climate model (GCM) ensembles, such as those performed under the Climate Model Intercomparison Projects CMIP3 and CMIP5, and from individual climate models. Results do disagree on the ranking (i.e. the relative importance) of the different feedbacks. Given the finding that an Arctic amplification without any contribution by the sea ice-albedo feedback is possible (Langen and Alexeev, 2007; Graversen and Wang, 2009), we suggest that the different feedbacks might compete and take over when selected feedbacks are hampered in a self-adjusting process. According to the example above, the cloud feedback plays the leading role if the sea ice-albedo feedback is disabled. If the sea ice-albedo feedback is active, it can dominate (Taylor et al., 2013).

Winton (2006) found that the Arctic amplification arises from "a balance of significant differences in all forcings and feed-backs between the Arctic and the globe". Given that processes are implemented differently in various GCMs, diverse states of that balance are possible in principle, and connected to different ranking of the feedbacks dominating the Arctic amplification, which might explain the spread in findings. Crook et al. (2011) and Taylor et al. (2013) suggest that the surface albedo feedback is the largest contributor to the polar amplification. Taylor et al. (2013) emphasize that this is the case for the annual mean and point out that the cloud feedback is the second largest contributor to the Arctic amplification. Winton (2006) and Pithan and Mauritsen (2014) agree on a contributory but not dominant role of the surface albedo feedback. Pithan and Mauritsen (2014) found the largest contribution to Arctic amplification arose from the temperature feedback, followed by the surface albedo feedback. Other contributions were found to be substantially smaller or even to oppose Arctic amplification.

While the regional amplifying effects of the sea icealbedo, cloud, temperature, and water vapour feedbacks appear comprehensible, a current relevant question is: to what extent are those effects triggered only by regional processes, or forced by water vapour transport and heat changed via large-scale circulation. There is some indication that the regional Arctic amplification is enhanced by increased largescale heat transport into the Arctic, as a dynamic response to the global scale water vapour feedback (Hansen et al., 2005). According to this hypothesis, water vapour transport is globally rearranged to even out the effect of the (positive) water vapour feedback in response to a warmer surface. The mechanisms involved are not fully understood, but a consequence of the hypothesized redistribution would be an inflow of water vapour into the Arctic. Model experiments (Langen et al., 2012, Boer and Yu, 2003) have supported this idea by analysing various feedbacks. Water vapour transport is found to change in a way that favours meridional response patterns (Langen et al., 2012).

Evaluating the level of understanding of the Arctic amplification, we may conclude that reasonable concepts of the physics of the albedo, cloud, water vapour, temperature feedback and Planck feedbacks readily exist. Challenges remain, both in the quantification of the strength of the feedbacks and in understanding the interactions between the various feedbacks. Evidence supports the hypothesis that competition exists between different feedback mechanisms, which might dynamically control the importance of the respective processes under changing conditions. The Arctic amplification is maintained even if specific feedbacks are suppressed. This ensures the existence of an Arctic amplification of atmospheric warming. For sea ice this could mean a stable forcing towards less ice, even if the sea ice is a part of the competition among feedback processes. Realistic representation of the feedbacks in climate models is an ongoing and complex task, as many of the feedbacks are related to subgrid-scale processes that require parameterization.

\subsection{Coupled Arctic variability}

Due to the Arctic's role as a heat sink with both oceanic and atmospheric heat flux components, changes of the largescale northward heat transports must affect Arctic temperatures. Away from the surface, northward heat fluxes are less influenced by regional Arctic feedbacks. In the free tropo- 
sphere away from the surface, Arctic temperature variations are mostly determined by meridional heat flux anomalies. Yang et al. (2010) found a 50\% positive and 30\% negative contribution of atmospheric heat transport anomalies to decadal Arctic temperature trends, based on reanalysis data in combination with microwave sounding estimates from polar-orbiting satellites during the 1980s and 1990s.

Model results indicate that variability in atmospheric and oceanic northward heat transports into the Arctic may compensate each other. Ocean heat transport anomalies "modulate sea ice cover and surface heat fluxes mainly in the Barents Sea/Kara Sea region and the atmosphere responds with a modified pressure field" (Jungclaus and Koenigk, 2010), which results in an atmospheric transport anomaly of the opposite sign. The compensation mechanisms are not active at all times, and are connected to atmospheric circulation patterns in the Pacific sector of the Arctic, especially to the second empirical orthogonal function (EOF) of the PacificNorth America (PNA) pattern.

Anomalous atmospheric large-scale transports of atmospheric moisture have been found which support sea ice melt by enhancing long-wave downward radiation. Effects of moisture transport are further described in Sects. 3 and 4.

The contribution of large-scale ocean heat transport into the Arctic is discussed in Sect. 5. In the Atlantic sector, a relation with the sea ice extent is well established (Koenigk et al., 2011; Holland et al., 2006), while direct impacts of Pacific inflow are difficult to prove.

Arctic sea ice variability and decadal scale changes can be generated both by regional Arctic processes (internally generated within the Arctic) or by global-scale forcing (externally forced by processes of a global or hemispheric scale). Attempts to quantify the relative importance of both process types rely on climate model ensemble studies. Studies (Mikolajewicz et al., 2005; Döscher et al., 2010) suggest that the variability generated by the external forcing on recent climate is more important in most coastal regions than the internally generated variability. Both are, however, of the same order of magnitude and the relative importance varies locally within the Arctic. The degree of external vs. internal variability also depends on the state of large-scale atmospheric circulation. Northerly wind anomalies in the Atlantic sector of the Arctic support ice export and favour external control on the ice extent, likely due to external influences on the wind anomalies forcing the ice export.

Additional model studies point at strong internal variability during the summer (Dorn et al., 2012; Holland et al., 2011). Summer sea ice volume is significantly affected by the atmospheric circulation, which in turn is largely influenced by large-scale atmospheric fields. Internal variability is particularly large in periods when the ice volume increases (Dorn et al., 2012).

\section{Arctic sea ice state and change}

\subsection{Sea ice extent}

Satellite-based observations of the Arctic sea ice extent exist since 1979 . The 34 year record documents the seasonal and interannual evolution in the Arctic sea ice cover. Sea ice extent has decreased for all seasons, with the strongest average decline in September $\left(84100 \mathrm{~km}^{2}\right.$ per year), and a moderate average decline during May of $33100 \mathrm{~km}^{2}$ per year (Meier et al., 2013). After 1999 (1999-2010), the negative decadal trend of summer sea ice extent intensified to $154000 \mathrm{~km}^{2}$ per year (Stroeve et al., 2012) and this period stands out as one of persistent decline, with record low September minima during 2002, 2005, 2007, and the latest record extent of $4.41 \times 10^{6} \mathrm{~km}^{2}$ in September 2012. The latest four record events after 2000 are documented in Fig. 1, which shows the sea ice concentration together with the average ice margin for the years 1992-2006. The figure was provided by the University of Hamburg and the SSM/I algorithms are described by Kaleschke et al. (2001).

The highest sea ice concentrations are found in the Arctic Ocean north of Greenland and in the Canadian Arctic Archipelago as a result of prevailing winds across the Arctic. The summer ice extents from 2005 to 2012 were all lower than the minimum between 1979 and 2004. The ice reduction is characterized by a pronounced ice retreat within the East Siberian, Chukchi and Beaufort seas and in the Barents and Kara seas. (Lindsay and Zhang, 2005; Comiso, 2006; Cuzzone and Vavrus, 2011). The shape of the remaining sea ice cover varies between the different record minima events. Since the late 1990s the Northeast Passage has been largely free of ice during September, with only small sea ice concentrations occurring, e.g. in September 2007. Even the Northwest Passage was largely ice free during September, starting 2007. Sea ice extent is also decreased during winter, mostly in the northern parts of the Barents Sea and in the northern North Pacific.

\subsection{Sea ice thickness and volume}

The accelerated decrease after 2000 has been accompanied by changes in ice thickness, volume, albedo and sea ice age, suggesting a true regime shift towards a "new Arctic". This term was inspired by the 2007 record sea ice low, and refers to a qualitative change in Arctic conditions fundamentally different to those from 1980-2000 (Comiso, 2006; Stroeve et al., 2007; Deser and Teng, 2008; Parkinson and Cavalieri, 2008; Liu et al., 2009).

Strong evidence exists for a decreasing Arctic sea ice volume, derived from occasional submarine-based upwardlooking sonar observations. Thickness has been measured measured in the central and western parts of the Arctic. The latest compilation, by Rothrock et al. (2008), covers the period 1975 to 2000 and gives a mean winter ice thickness de- 
cline, from a peak of $3.78 \mathrm{~m}$ in 1980 to a minimum of $2.53 \mathrm{~m}$ in 2000 . This is a decrease of $1.25 \mathrm{~m}$ over 20 years. The mean annual cycle of sea ice thickness amounts to $1.12 \mathrm{~m}$.

Altimeter equipped satellites operated during the first years of this century (ICESat, 2003-2008), were capable of measuring the ice thickness with an uncertainty of 40-70 cm (Laxon et al., 2003; Kwok et al., 2009). Thin ice with thickness less than 0.5 to $1 \mathrm{~m}$ in the marginal ice zone was excluded from analysis due to large uncertainties. Under those limitations, the winter sea ice thickness reduction from the submarine-based observations until the year 2000 were extended to a thickness down to $1.89 \mathrm{~m}$ in 2008 (Kwok and Rothrock, 2009). Those values show an accelerated thickness loss after year 2000 .

Estimates of overall Arctic sea ice volume have long been challenging due to incomplete coverage of ice thickness data and its seasonal cycle. As a best guess approach, ocean-sea ice models, annually initialized with observed sea ice concentrations, can be used to infer sea ice volume. The PanArctic Ice Ocean Modeling and Assimilation System (PIOMAS, Zhang and Rothrock, 2003) gives a trend over a 32 year period (1979-2011) of $-2800 \mathrm{~km}^{3}$ per decade for October (Schweiger et al., 2011). Recent absolute volumes range between $28700 \mathrm{~km}^{3}$ in April and $12300 \mathrm{~km}^{3}$ in September. PIOMAS uncertainty is estimated to be $350 \mathrm{~km}^{3}$ for October. Since the 1980s, the sea ice volume has reduced at a greater rate than the extent. By the mid-1990s, volume losses in September exceeded ice extent losses by a factor of four in PIOMAS. Since then, the volume/extent anomaly ratios have reduced, and are now around two (Schweiger et al., 2011).

New satellite data from the European Space Agency CryoSat-2 mission allow ice thickness estimates with an uncertainty of $0.1 \mathrm{~m}$ in comparison with independent in situ data, when averaged over a large region (Laxon et al., 2013). Starting in 2011, sea ice volume loss over autumn and winter was about $500 \mathrm{~km}^{3}$ per year (corresponding to $0.075 \mathrm{~m}$ per year in thickness), which fits well with peak thinning rates from submarine-based observations. Between the ICESat (2003-2008) and CryoSat-2 (2010-2012) operational periods, the autumn volume declined by $4291 \mathrm{~km}^{3}$ and the winter volume by $1479 \mathrm{~km}^{3}$ (Laxon et al., 2013). The seasonal cycle of volume loss and gain from CryoSat-2 is greater than that from PIOMAS. Longer term measurements by CryoSat2 will enable long-term estimates of ice volume development.

Recent re-interpretation of ICESat data has enabled trends in sea ice volume of $-1445 \pm 531 \mathrm{~km}^{3}$ per year in October/November and $-875 \pm 257 \mathrm{~km}^{3}$ per year in February/March to be obtained (Zygmuntowska et al., 2014). Taking into account algorithm uncertainties due to assumptions of ice density and snow conditions, the hypothesized decline in sea ice volume in the Arctic between the ICESat and CryoSat-2 operational periods may have been less dramatic (Zygmuntowska et al., 2014) than reported in Laxon et al. (2013).
The total annual sea ice volume budget is controlled by summer ice melt, wintertime ice accumulation, and the ice export. Naturally, those components of the volume budget depend on each other. As an example, ice growth increases material ice strength, which in turn reduces ice speed. This potentially reduces the area of leads, which feeds back on ice growth.

Coupled atmosphere-ice-ocean numerical models are the principle tools for investigating sea ice volume budgets on seasonal and yearly scales within the vast Arctic Ocean region. Derived from an ensemble of GCMs for recent climate conditions (1980-1999), a total melt of $1.1 \mathrm{~m}$ and an export of $0.2 \mathrm{~m}$ is balanced by $1.3 \mathrm{~m}$ of ice growth during the winter (Holland et al., 2010). These figures largely agree with observation-based estimates derived from an Arctic heat budget combined with assumptions of the latent heat of fusion and sea ice density (Serreze et al., 2007a).

Locally in the Beaufort Sea and around the North Pole, typical melting and growth rates have been about $20-50 \mathrm{~cm}$ per season. This was the situation before the 2007 sea ice record minimum. During the 2007 event, the Beaufort Sea bottom melting increased to about $200 \mathrm{~cm}$ (Perovich et al., 2008), explained by anomalously large fractions of open water that allowed increased heat absorption by the ocean with subsequent lateral heat distribution underneath the ice.

Melt-export-growth imbalances have increased since 2000. In the Fourth Assessment Report (AR4) of the Intergovernmental Panel on Climate Change (IPCC), GCMs were shown to largely agree on a decrease of ice volume resulting from increased annual melt during the melt season, rather than reduced growth during winter. This picture holds for predictions of the first half of the 21st century and is later reversed towards a dominance of reduced winter growth for the second half of the 21 st century.

\subsection{Sea ice age}

Arctic sea ice is composed of multi year (perennial) and first year (seasonal) ice types. Sea ice thickness can be characterized by its age and the degree and type of deformation. The largest undeformed ice floe thickness is estimated to culminate at $1.5-2 \mathrm{~m}$ for the first year ice and at $3-3.4 \mathrm{~m}$ for 7-9 year old ice-types. Pressure ridges can be as high as $20 \mathrm{~m}$ a.s.l., especially in coastal areas, but also in deeper areas such as the Beaufort Sea (Bourke and Garrett, 1987; Melling, 2002). Ridges can grow even larger under the water surface.

There is good agreement on recent thinning between different data sources throughout the Arctic Ocean (Comiso et al., 2008; Kwok et al., 2009; Maslanik et al., 2011). This shrinking occurs primarily at the expense of the multi year sea ice and thinning of ridged ice, while the thickness changes within the shifting seasonal ice zone are negligible (Rothrock and Zhang, 2005; Comiso, 2006; Nghiem et. al., 2007; Kwok et al., 2009). Among the multi year ice types, 


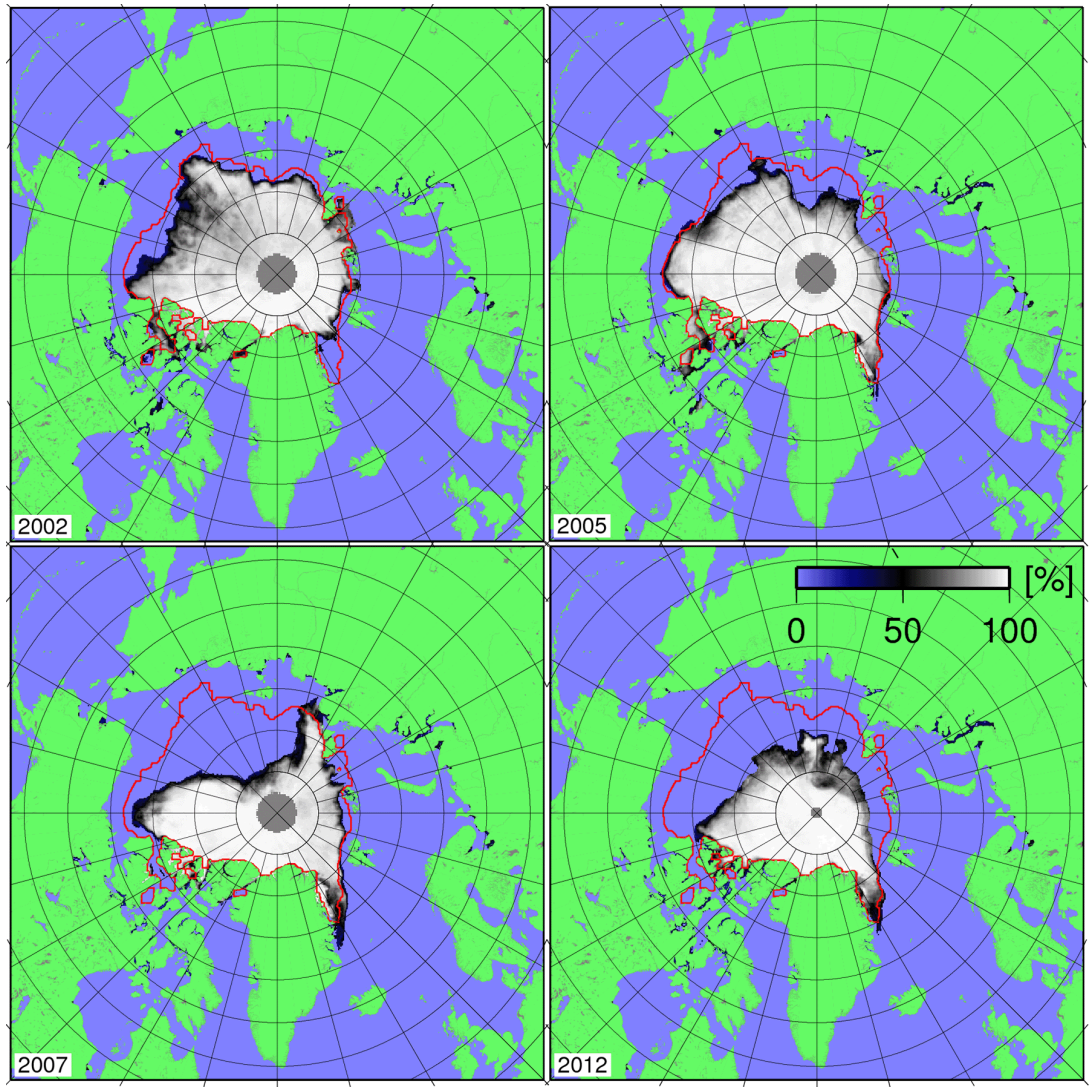

Figure 1. Monthly mean sea ice concentration (white to blue), based on SSM/I data for September 2002, 2005, 2007 and 2012, with the average ice margin (red) for the years 1992-2006. Pictures provided by Lars Kaleschke of the University of Hamburg. The SSM/I algorithms are described by Kaleschke et al. (2001).

the most extensive loss is seen for the oldest ice types. The fraction of total ice extent made up of multi year sea ice in March decreased from about $75 \%$ in the mid 1980s to $45 \%$ in 2011, while the proportion of the oldest ice declined from $50 \%$ of the multi year ice pack to $10 \%$. By 2011, sea ice older than 5 years had almost vanished (Maslanik et al., 2011; from $2.810^{3} \mathrm{~km}^{2}$ in the 1980 s to $0.410^{3} \mathrm{~km}^{2}$ in 2011). In terms of ice thickness, the mean value of the former perennial and now seasonal ice zone was about 3-3.4 m during the autumn-winter season in 2003-2004, and approximately 2.3-2.8 m during 2007-2008 (Kwok et al., 2009). After summers with record low sea ice extent, the fraction of multi year ice increases temporarily while the long-term trend remains negative (Maslanik et al., 2011).

The major change in sea ice thickness distribution towards first year ice is accompanied by a longer term decrease in the occurrence of thick pressure ridges in the central Arctic since the 1970s. Pressure ridges greater than $9 \mathrm{~m}$ (sum of ridge height and keel depth) showed a drop of $73 \%$, as a result from comparing two older submarine missions in 1976 and 1996 (Wadhams and Davis, 2000). It is hypothesized that deep pressure ridges are more susceptible to bottom melting due to the large porosity of the deep ice ma- terial which allows for more efficient melting once the water warms (Amundrud et al., 2006, Wadhams, 2013). Despite local increase of ridge population due to increased ice moveability, there is a long-term trend towards less deep ridges (Wadhams, 2013).

\subsection{Sea ice motion}

Arctic sea ice is constantly in motion under the effect of winds, ocean currents, tides, the Coriolis force, sea surface tilt, and the internal resistance of the ice pack. The local airice momentum flux is usually the dominating forcing factor, and depends on the local wind speed, thermal stratification, and aerodynamic roughness of the surface. Under stress the sea ice floes crush, diverge and build-up pressure ridges. Recent changes in the ice drift have mostly been associated with changes in the internal resistance and atmospheric forcing; these effects are discussed below.

Arctic sea ice motion closely mirrors the background atmospheric circulation patterns (Inoue and Kikouchi, 2007). In winter, a well developed Beaufort High in the western Arctic, and frequent and intense cyclonic motion in the eastern Arctic, remove sea ice from the Siberian coast (i.e. in the 
Laptev, Kara and East Siberian seas) towards Greenland and the Fram Strait. In summer those transpolar winds and related ice drift speeds weaken. Day-to-day variability of surface winds modulate the ice drift trajectories and velocities. Ice drift speeds have a range of $0-25 \mathrm{~km}$ per day (Zhao and Liu, 2007).

Interannual variability in the monthly mean ice drift has been attributed to the predominant atmospheric circulation patterns, such as the Arctic Oscillation (AO), the North Atlantic Oscillation (NAO), the Dipole Anomaly (DA; the second leading mode of sea-level pressure anomaly in the Arctic), and the Central Arctic Index (CAI). Wu et al. (2006) define the DA as a dipole anomaly corresponding to "the second-leading mode of EOF of monthly mean sea level pressure north of $70^{\circ} \mathrm{N}$ ". Earlier, Skeie (2000) found the second EOF of monthly winter sea level pressure anomalies poleward of $30^{\circ} \mathrm{N}$, named the "Barents Sea anomaly", to be highly influential on Eurasian climate. Overland and Wang (2010), referring to an analysis area north of $20^{\circ} \mathrm{N}$, found a third EOF mode, which they called the Arctic Dipole (AD), reminiscent of the "Barents Sea anomaly" of Skeie (2000). Thus, the definitions of second or third modes vary. All versions commonly point at variability modes introducing meridional circulation components.

The close relationship of ice drift with the AO and NAO is well-known (e.g. Inoue and Kikouchi, 2007; Kwok et al., 2009). Maslanik et al. (2007) suggested, however, that the $\mathrm{AO}$ is not a reliable indicator of the ice drift patterns that have favoured sea ice decline in the western and central Arctic since the late 1980s. Also X. Zhang et al. (2008) suggested a decreasing control of the positively-polarized AO and NAO on the Arctic sea ice cover. The importance of the DA was demonstrated by Wu et al. (2006) and Wang et al. (2009). Recent work under the DAMOCLES project has, however, shown that over most of the Arctic the annual mean ice drift speed forcing is better explained by the CAI, calculated as the sea level pressure difference across the Arctic Ocean along meridians 270 and $90^{\circ} \mathrm{E}$ (Vihma et al., 2012). The drift speed is more strongly related to the CAI than to the DA partly because the CAI is calculated across the Transpolar Drift Stream (TDS), whereas the pressure patterns affecting the DA sometimes move far from the TDS. CAI also has the benefit of being insensitive to the calculation method applied, whereas the DA, as the second mode of a principal component analysis, is sensitive both to the time period and area of calculation (Vihma et al., 2012). Arctic-wide and different combinations of atmospheric circulation indices (such as the CAI, DA and AO) explain $48 \%$ of the variance of the annual mean ice drift in the circumpolar Arctic; $38 \%$ in the eastern Arctic; and $25 \%$ in the Canadian Basin (Vihma et al., 2012).

Sea ice drift velocities have gradually increased since the 1950s. Significant positive trends are present in both winter and summer data (Häkkinen et al., 2008). The Arctic basin-wide averaged drift speed between 1992 and 2009 in- creased by $10.6 \%$ per decade (Spreen et al., 2011). The trend is strongest after 2004 with an average increase of $46 \%$ per decade. The drift of the sailing vessel Tara in 2006-2007 in DAMOCLES was almost three times faster than that of Fram in 1893-1896 (Fig. 2) along a similar path in the central Arctic (Gascard et al., 2008), but the contributions of various forcing factors to the difference is not quantitatively known. The winds experienced by Tara were rather weak but their direction favoured the transpolar drift (Vihma et al., 2008). The TDS has strengthened especially in summer between the late 1970s and 2007 (Kwok, 2009).

Considering the ice drift evolution from the 1950s to 2007, Häkkinen et al. (2008) identified the primary reasons for the ice drift trend as increasing wind speed, related to increased storm activity over the TDS. Drift speed changes after the year 2000 are also connected to net strengthening of ocean currents in the Beaufort Gyre and the transpolar drift, propelled by a positive DA for the mean summer circulation (2001-2009), which also enhances summer sea ice export through the Fram Strait (Kwok et al., 2013). Zhang et al. (2003) emphasized the role of ice thickness, both in the Fram Strait and north of it, on the total sea ice export.

Rampal et al. (2009) and Gimbert et al. (2012) found that the increase in drift speed since 1979 was related to thinner sea ice with reduced mechanical strength. Spreen et al. (2011) detected signs of both wind and ice thinning effects in 1992-2009, with the ice thinning likely more important. According to Vihma et al. (2012), atmospheric forcing cannot explain the increasing trend in drift speed in the period 1989-2009, but can explain a large part of the interannual variance, not be explained by changes in ice thickness.

More information arises from recent reports on the impact of younger ice. Regionally, "positive trends in drift speed are found in regions with reduced multi year sea ice coverage. Over $90 \%$ of the Arctic Ocean has positive trends in drift speed and negative trends in multi year sea ice coverage" (Kwok et al., 2013). Changes in wind speed explain only "a fraction of the observed increase in drift speeds in the Central Arctic but not over the entire basin" (Spreen et al., 2011). In other regions, it is the ice thinning that is the more likely cause of the increased ice drift speed. Reviewing the above papers, explaining increased ice drift speeds, points to an increasing importance of the effects of thinning and age for the more recent past, while increased wind speeds dominate before 1990.

A direct consequence of increased ice speeds is a temporally increased sea ice export through the Fram Strait (Kwok et al., 2013). Buoy data from 1979 to the mid-1990s suggest an increasing trend in the ice area export via the Fram Strait, mostly due to a positive phase of the AO (Polyakov et al., 2012). Increased ice movement also contributes to specific events of rapid ice extent loss. During 2007, first year ice from the Chukchi Sea intruded into the northern Beaufort Sea. Combined with increased poleward summer ice transport from the western Arctic, a reduced fraction of multi 


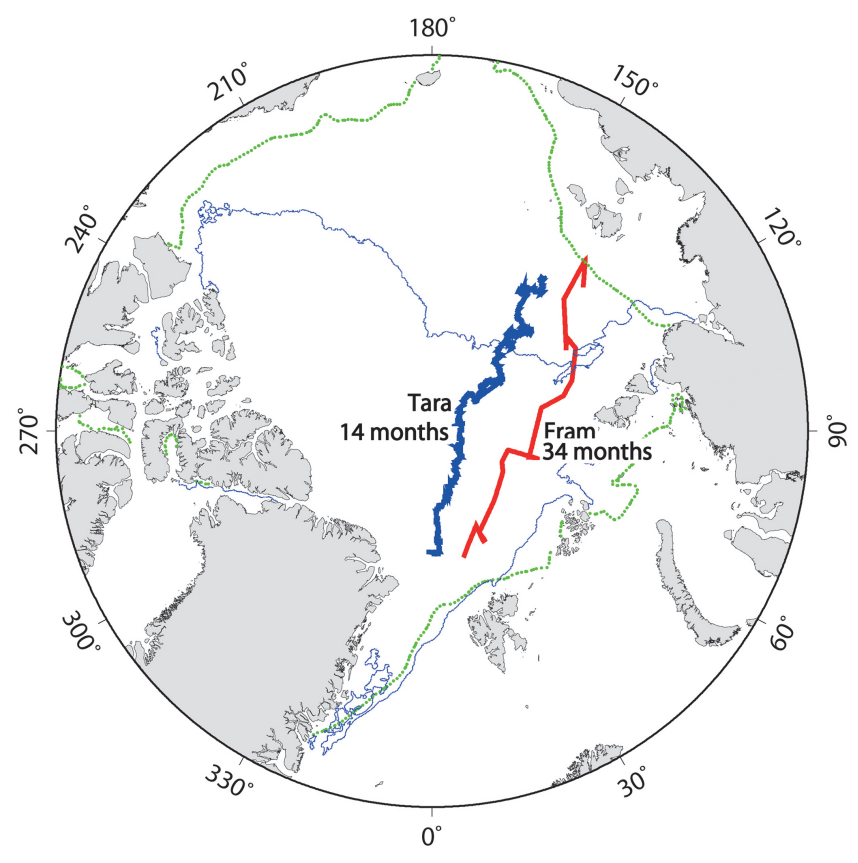

Figure 2. Drift trajectories of the vessels Tara (blue, November 2006-January 2008) and Fram (red, October 1893-August 1896). The sea ice edges are displayed for September 2007 (blue) and for the September mean 1979-1983 (green).

year ice provided the basis for the 2007 record minimum event (Hutchings and Rigor, 2012). Ice loss through Fram Strait export is stimulated by certain local winds. Sea ice export variability is strongly determined by variations in the sea level pressure gradient across the Fram Strait. This finding is based on numerical simulations with a GCM (Koenigk et al., 2006), and supported by analysis of ice export observations in relation to atmospheric reanalysis (Tsukernik et al., 2010). Positive CAI and DA were observed during summer 2007, coinciding with an increased ice export (J. Zhang et al., 2008). Note that increased summer export does not play a major role in explaining the record low events due to the small overall amounts compared to winter export. Before 2007, between 1979 and 2006, no significant summer sea level pressure forcing of Fram Strait ice motion was found. A generally increased Fram Strait ice area export on a decadal scale cannot be detected (Spreen et al., 2009). A slight increase in the sea level pressure gradient, potentially forcing increased ice export, is compensated by a parallel decrease in the sea ice concentration (Kwok et al., 2009; Polyakov et al., 2012).

As the ice thins and is subject to increased weather impacts, even the frequency of cyclones during late spring and summer affects the summer sea ice area. Low September sea ice areas are generally connected to below normal cyclone frequency during spring and summer over the central Arctic. Fewer cyclones lead to increased sea level pressure, enhanced anticyclonic winds, a stronger transpolar drift stream, and reduced cloud cover, all of which favour ice melt (Screen et al., 2011). Thus, storm activity over the central Arctic has a preconditioning effect on the outcome of the summer sea ice area and extent. An obvious question is whether the storm activity over that region has changed during the recent decades. Observations show a northward shift of storm tracks, which is discussed in further detail in Sect. 4.

\subsection{Snow and freezing/melting processes}

Ice floes in winter are almost always covered by snow. The snow depth varies between $0-100 \mathrm{~cm}$ on horizontal distance scales of 10-100 m; this is no relationship between the ice type and ice thickness, except that in winter only thin, young ice in refrozen leads is free of snow (Walsh and Chapman, 1998; Perovich et al., 2002; Perovich and Richter-Menge, 2006; Gerland and Haas, 2011). The low thermal conductivity and high heat capacity of snow explain how the snowpack acts as a good insulator for sea ice. In the presence of snow, the response of the sea ice temperature to perturbations in air temperature is much weakened.

Little is known about changes in snow thickness on top of sea ice. The most extensive snow thickness information available is based on measurements made at the Russian drifting stations from 1954-1991 (Radionov et al., 1997) and airborne expeditions with landings on sea ice from 19371993, but there are no contemporary, systematic, basin-scale in situ observations. Snow thickness estimates based on remote sensing have been developed (Brucker et al., 2014), but they are not accurate over deformed ice and multi year ice in general. On the basis of the ERA-Interim reanalysis, Screen and Simmonds (2012) detected a pronounced decline in summer snowfall over the Arctic Ocean between 1989 and 2009. This was caused by a change in the form of precipitation, as snow turned into rain due to lower-tropospheric warming. This resulted in a reduced surface albedo over the Arctic Ocean, which they estimated to have an order of magnitude comparable to the decrease in albedo due to the decline in sea ice cover. Thus, the decline in summer snowfall has likely contributed to the thinning of sea ice during recent decades.

Satellite retrievals of the spring onset of snowmelt, from both passive and active microwave observations, demonstrate the long-term tendency towards earlier surface melt, with a mean of about 2.5 days per decade in the central Arctic (Markus et al., 2009), locally reaching 18 days per decade, especially within the central western Arctic (Maksimovich and Vihma, 2012). Concurrently, the fall freeze-up appears to be more and more delayed in the season (Markus et al., 2009), both within the open sea and on top of the sea ice that survived the melt season. Over time, these two essential processes - spring melt onset and fall freeze-up - affect the sea ice extent, thickness and volume in a non-linear way (Maksimovich and Vihma, 2012). An earlier surface melt initiation of just a few days (typically occurring May-June) drastically 
increases the absorption of solar energy, and the effect propagates through the entire melt season.

Radiation measurements in the central Arctic, in combination with numerical experiments, allow quantification of the contribution of the earlier spring melt initiation and later fall freeze-up (Perovich et al., 2007b). A spring melt early by one day corresponds to an additional ice melt of $3 \mathrm{~cm}$ during the melt-season. In contrast, a fall freeze-up (typically occurring in late August-November) delay of one day contributes about $0.5 \mathrm{~cm}$ of summer ice melt in the same season. As a positive feedback, the earlier spring melt contributes to earlier ice thinning, and further additional heat storage in the upper ocean during the melt season (Frey et al., 2011), thus retarding the fall freeze-up (Armstrong et al., 2003; Gerdes, 2006; Perovich et al., 2007a, b). The spring melt initiation and the fall freeze-up timing are statistically related (Maksmovich, 2012), in particular in the eastern Arctic Basin covered by first year ice. The delayed ice formation plays a major role in the atmospheric warming during the early polar night season. As an example, the ocean heating of the lower atmosphere was nearly three times greater in September-November during years with exceptional ice retreat (2005-2007) compared to earlier years with larger summer ice extents (Kurtz et al., 2011).

The atmospheric thermodynamic forcing on sea ice thickness is transmitted via radiative and turbulent surface fluxes. Our knowledge of the climatology of radiative and turbulent fluxes is based on only a few observations: the year-round Surface Heat Budget of the Arctic Ocean (SHEBA) campaign being the most important (Persson et al., 2002). The radiative fluxes are typically larger in magnitude than the turbulent fluxes. In winter, the upward long-wave radiation exceeds the downward component; the negative long-wave radiation flux on the snow surface is typically balanced by a downward sensible heat flux and heat conduction through the ice and snow. The latent heat flux is close to zero in winter. In summer, net short-wave radiation is the dominating flux, the net long-wave radiation flux is less negative than in winter, the latent heat flux is upwards, and the sensible heat flux may be either upwards or downwards (Persson et al., 2002). Unfortunately there are not enough observations available to estimate possible trends in the turbulent surface fluxes. For moisture fluxes, see Sect. 4.3.

Albedo at the surface of sea ice, or snow on top of sea ice, is the crucial property limiting the effect of short-wave radiation on the ice (for recent advances in physics and parameterizations, see Vihma et al., 2014). Values for albedo at the ice or snow surface have long been derived from local direct observations. Improvements have arisen from satellite based algorithms, which allow the long-term temporal development of ice or snow albedo to be accessed. Albedo trends during the 1980s and 1990s were rather weak compared to the trends after the mid 1990s (Wang and Key, 2005). Laine (2004) found a surface albedo trend for the Arctic Ocean close to zero, based on the Advanced Very High Resolution Radiome- ter (AVHRR) Polar Pathfinder satellite observations for the years 1982-1998. Later, a long-term decrease of the albedo in the sea ice zone has been detected (Riihelä et al., 2013) based on data products from the Satellite Application Facility on Climate Monitoring (CM SAF) covering 1982-2009. For the mean August sea ice zone (all surface areas with more than $15 \%$ sea ice concentration), a significant trend of -0.029 per decade has been found for the albedo measurements (Riihelä et al., 2013). This even includes the effect of leads, which have a much lower albedo than any type of sea ice. Both increased lead areas and reduced ice surface albedo contribute to the trend.

Earlier timing of the melt onset is an important influence on reduced sea ice albedo (see above). For comparison, simulated recent climate between 1982 and 2005 within the CMIP5 project gives a cross-model average albedo trend of -0.017 per 24 years (Koenigk et al., 2014), corresponding to -0.0071 per decade. This is about half of the observed trend. Climate models in CMIP5 show large differences in albedo formulations and values.

Sea ice albedo depends on a range of influences (e.g. ice thickness, age, temperature, melt pond fraction, and length of melting/freezing seasons). Melt ponds on the ice reduce the sea ice albedo (Perovich et al., 2011). A quantification of the Arctic-wide melt pond occurrence and effects requires satellite observations. Recent progress in algorithm development has enabled observations over complete melting periods. Anomalously high melt pond fractions are found during the summers of the record low sea ice years of 2007 and 2012, based on the Moderate Resolution Imaging Spectroradiometer (MODIS) satellite sensor (Rösel and Kaleschke, 2012). However, long-term trends of melt pond fractions cannot be detected with statistical significance.

The important role of melt ponds on sea ice albedo is supported by numerical simulations of Arctic climate. Under recent climate conditions, melt ponds predominantly develop in the continental shelf regions and in the Canadian Arctic Archipelago. Use of melt pond parameterizations, compared to classical albedo formulations with either no or only very simplistic recognition of melt ponds, lead to systematically reduced albedos, enhanced sea ice melt, reduced summer ice thickness and concentration (Karlsson and Svensson, 2013; Roeckner et al., 2012; Flocco et al., 2012) and contribute about $1 \mathrm{~W} \mathrm{~m}^{-2}$ to the forcing of ice melt (Holland et al., 2012).

Sea ice melt is further exacerbated by deposition of atmospheric aerosols (dust and soot) on the highly reflective snow and bare ice surface, reducing the surface albedo. In the presence of soot, the absorption of solar radiation is more efficient and the internal heat storage is larger, supporting earlier and faster snowmelt (Clarke and Noone, 1985; Grenfell et al., 2002). Black carbon has been identified as the dominant absorbing impurity. The effect on climate forcing is estimated to be $+0.3 \mathrm{~W} \mathrm{~m}^{-2}$ in the Northern Hemisphere (Hansen and Nazarenko, 2004), and $+0.6 \mathrm{~W} \mathrm{~m}^{-2}$ globally, 
compared to a total $2.3 \mathrm{~W} \mathrm{~m}^{-2}$ (IPCC AR5) in anthropogenic radiative climate forcing. GCM studies have confirmed this effect (Roeckner et al., 2012; Holland et al., 2012). Recently, the effects of soot on different ice types has been recognized. Given a background of black carbon on the ice, first year sea ice is more sensitive to black carbon additions compared to multi year ice (Marks and King, 2013). First year sea ice scatters incoming radiation to a lesser degree than multi year ice. This points to a positive feedback of the growing dominance of first year ice, which facilitates stronger melting due to a more efficient albedo reduction by black carbon. The situation is complicated by fresh snow covering the soot already on the ice, thereby temporarily mitigating the effect.

We are witnessing an Arctic sea ice pack that is thinning, becoming younger and more moveable, with a decreasing albedo and lengthening melting season. All these trends and effects cause the ice cover to be more susceptible to quickly responding to a warming climate. In this sense, the Arctic climate system has reached a new era with decreased stability of the ice cover.

\subsection{Challenges in the understanding of sea ice evolution and sources of uncertainty}

Understanding of sea ice state variability and trends is made challenging because the available information on changes in sea ice thickness is inaccurate, in particular for the summer period. Still much less is known about potential changes in snow thickness on top of sea ice. Key results, such as the findings by Screen and Simmonds (2012) on the decrease of snowfall and increase of rain over the Arctic Ocean, are based on reanalysis data, which cannot be verified by direct observations. A spatially and temporally extensive precipitation change from snowfall to rain may have even more potential to reduce sea ice albedo than, for example, black carbon.

Further uncertainty arises from imperfect estimates of sea ice extent and concentration. Depending on the processing algorithm applied to the microwave satellite data, the Arctic sea ice extent may still have an uncertainty of up to $1 \times 10^{6} \mathrm{~km}^{2}$ (Kattsov et al., 2010). The treatment of new, thin ice in refrozen leads is one of the factors generating scatter in the results. The generation of consistent time series over long periods is challenging because of the sensor degradation of instruments onboard satellites (Cavalieri and Parkinson, 2012). Further, changes of the ice type, level of fracturing, amount of superimposed ice, and areal coverage of melt ponds are not well-known. However, various new and anticipated satellite remote sensing products, combined with thermodynamic modelling, may soon improve the situation.

To assess an accurate mass and volume budget for Arctic sea ice, thickness information is essential. Published results on ice drift and export demonstrate a large interannual and decadal variability. The recent increase in ice drift speed is mostly due to ice becoming thinner and mechanically weaker. The effects of increased drift speed and de- creased ice concentration have balanced each other so that there is no long-term trend in the ice area flux out of the Fram Strait. Hence, as the ice thickness has decreased, so too has the volume of transported ice. Despite this, the relative importance of ice export in the mass balance of Arctic sea ice has not necessarily reduced, as the ice volume in the Arctic has decreased together with the volume transport.

The picture of the Arctic sea ice that emerges is one becoming thinner and younger, and reducing in extent. Despite uncertainties, this picture is robust because the signal is strong and verified through different sources. However, understanding of the specific mechanisms, and detailed budgets, is still vague. This is especially true for the changing sea ice volume components and snow processes.

\subsection{Future sea ice projection and prediction}

Global climate models are tools supporting an integrated understanding of the Arctic climate system and its link with other geographical areas. Although imperfect by definition, models allow for process studies and future climate projections including assessment of uncertainty. The GCMs of the CMIP5 project, tend to underestimate the sea ice decline when run for observed periods and the results differ greatly between models (Massonet et al., 2012). (Note: in contrast to climate prediction, CMIP5 simulations are not initialized with recent observations and suffer from natural variability not necessarily in phase with reality). Identifying subsets among the simulations, those models with near-realistic atmospheric circulation better simulate the decline of the sea ice extent after 2000. However, many models suffer from a circulation bias. A large uncertainty is also seen in sea ice future projections, related to a generally slow rate decrease or too late a sea ice drop. Other reasons are seen in the different models' parameterizations, biases in the atmosphere, ocean, and ice, and the coupling between the component models. Model differences of sea ice albedo also contribute to the large uncertainties in the Arctic climate as simulated by GCMs (Hodson et al., 2013), and result in large differences for the Arctic radiation balance (Karlsson and Svensson., 2013).

Future progress in the ability to simulate Arctic sea ice requires better quantification of heat exchange between sea ice, atmosphere and ocean. It will also be necessary to reduce model circulation biases.

Sea ice prediction (different from projection) on a seasonal to decadal timescale requires careful initialization with ocean and sea ice conditions. Additional potential is seen in coupled initialization of land. When initialized climate models are run in ensemble mode (several runs differing slightly only in initial conditions), the spread of the results can be explored to assess the potential predictability of the Arctic, i.e. the upper limit of climate predictability on seasonal to decadal timescales. The decadal average sea ice thickness is highly predictable along the ice edges in the North Atlantic-Arctic 
Sector (Koenigk et al., 2012), due to a strong correlation with the meridional overturning circulation in the North Atlantic Ocean. Such results suggest that the outlook is positive for future climate prediction in the Arctic.

\section{The role of the atmosphere and its impact on sea ice}

The atmosphere interacts with the Arctic sea ice decline via thermodynamic effects on ice melt and dynamic effects on ice drift (the latter is discussed in Sect. 3.4). The direct thermodynamic atmosphere-sea ice coupling occurs via the radiative and turbulent surface fluxes, whereas precipitation has a strong indirect effect on this coupling via modification of radiative fluxes, surface albedo and snow thickness (Sect. 3.5). Meteorological observations over sea ice are limited, and direct measurements of surface fluxes and precipitation are extremely rare. Coastal observations are not representative for the sea ice zone. Radiative and turbulent surface fluxes from atmospheric reanalyses have large errors (Wesslén et al., 2013; Tastula et al., 2013) and the quality of reanalyses' precipitation data over sea ice is poorly known (Jakobson and Vihma, 2010). Hence, much of our observationallybased knowledge of atmospheric-driven thermodynamic effects on sea ice decline originates from analysis of processes and variables that indirectly, rather than directly, affect sea ice melt and growth.

Among the relevant atmospheric conditions for Arctic sea ice change are the large-scale circulation patterns, characterized, among others, by the AO, NAO, and DA (as introduced in Sect. 3.4). Large-scale circulation patterns are inherently and interactively related to cyclone statistics and properties. Cyclones are responsible for a major part of the transport of heat and water vapour into the Arctic. Essential characteristics of the Arctic atmosphere also include cloud coverage and properties, and the vertical structure of the atmosphere, from the atmospheric boundary layer (ABL) to the stratosphere.

\subsection{Large-scale circulation and cyclones}

Large-scale oscillation patterns have been influential in preconditioning and forcing the observed sea ice decline at times. Both observational and modelling studies have demonstrated that the positive polarity of the AO or NAO drove a decrease in sea ice extent or thickness between 1980 and the mid 1990s. This is the dominating large-scale driving effect on sea ice during that time period. Since 1950 (the start of regular monitoring) the 1980-1995 period stands out as having an anomalously high average amplitude of the NAO index. In addition to the change in polarity and amplitude, the relation between sea ice and the NAO was less efficient, because the NAO pattern shifted spatially around 1980 (Hilmer and Jung, 2000). Such spatial shifts have been shown to impact Arctic temperatures throughout the 20th century, char- acterized by varying angles of the axis between the NAO's centres of action (Jung et al., 2003; Wang et al., 2012).

During the positive NAO/AO years after 1980, and especially during the most positive years of 1989-1995, altered surface winds resulted in a more cyclonic ice motion and a more pronounced Transpolar Drift Stream (TDS) connected to enhanced ice openings, thinner coastal ice during spring and summer, and to increased sea ice exportation (Rigor et al., 2002; Serreze et al., 2007b). The continued downward trend of sea ice extent after the mid 1990s is interpreted as a delayed response, in addition to other effects such as the ongoing increase of atmospheric temperatures (Lindsay and Zhang 2005). In the 2010/2011 winter, a strongly negative AO was observed (Stroeve et al., 2011). Maslanik et al. (2011) argued that this explains a recent partial recovery of the multi year ice extent (see Sect. 3.3).

During this century, the large-scale circulation in the Arctic has changed from a zonally dominated circulation type, which can be well characterized by the AO, to a more meridional pattern characterized by the $\mathrm{AD}$, where a high pressure centre is typically located in the Canadian Arctic and a low in the Russian Arctic (Overland and Wang, 2010). This favours advection of warm, moist air masses from the Pacific sector to the central Arctic, contributing to sea ice decline (Graversen et al., 2011) and rapid sea ice loss events (Döscher and Koenigk, 2013). Through increased release of ocean heat into the atmosphere during autumn, the sea ice decline has, in turn, contributed to a modification of large-scale atmospheric circulation, favouring a positive $\mathrm{AD}$ (Overland and Wang, 2010).

Another noteworthy aspect of recent large-scale circulations is that, for the past six years, strong Arctic warming has not been supported by positive values of the Pacific Decadal Oscillation (PDO) index (Walsh et al., 2011). The AO, DA/AD, and PDO closely interact with cyclone statistics. Cyclone activity is most vigorous in the Greenland Sea during all seasons, except summer, when the Norwegian, Barents and Kara seas have a comparable amount of activity (Sorteberg and Walsh, 2008). The number of cyclones travelling into the Arctic is similar in all seasons, but in winter the cyclones are more intense and shorter than during summer.

Approaches to Arctic cyclone statistics exist since the 1950 s, with very limited observations. More complete surveys were undertaken by e.g. Serreze et al. (1993), and McCabe et al. (2001), revealing a positive trend of winter Arctic cyclone frequency for the period 1952-1997.

More recent studies have addressed recent changes in synoptic-scale cyclones in the sub-Arctic and Arctic. A statistically significant increasing trend in the frequency of cyclones entering the Arctic during recent decades has been detected, e.g. by Zhang et al. (2004), Trigo (2006), Sorteberg and Walsh (2008), and Sepp and Jaagus (2011), suggesting a shift of cyclone tracks into the Arctic, particularly in summer. Analogous to synoptic-scale cyclone movements, polar lows have migrated northward (Kolstad and Bracegir- 
dle, 2008; Zahn and von Storch, 2010), perhaps due to the retreating sea ice margin.

According to Sepp and Jaagus (2011), however, the frequency of cyclones formed within the Arctic basin has not increased. Zhang et al. (2004) and Simmonds and Keay (2009) also report an increase in the intensity of cyclones entering the Arctic from the mid-latitudes. Zhang et al. (2004) further found that Arctic cyclone activity displays significant lowfrequency variability, with a negative phase in the 1960s and a positive phase in the 1990s. Over smaller sea areas, such as the Bering and Chukchi seas, the trends in cyclone activity since 1948 have been weak (Mesquita et al., 2010).

Since a strong storm event in the Beaufort Sea during August 2012 (Simmonds and Rudeva, 2012), the effect of summer storms on sea ice has received a lot of attention. According to a modelling study by Zhang et al. (2013), the strong melt was largely due to a quadrupling in bottom melt, caused by storm-driven enhanced mixing in the ocean boundary layer. Zhang et al. (2013) argued, however, that a record minimum ice extent would have been reached in 2012 even without the storm. It should be noted that summer cyclones in the Arctic are climatologically weak and do not usually generate storm-force winds (defined as 10 minute mean wind speed exceeding $20 \mathrm{~m} \mathrm{~s}^{-1}$ ). For example, the SHEBA ice station and Tara mission did not experience a single summer day with wind speed exceeding $20 \mathrm{~m} \mathrm{~s}^{-1}$ (Vihma et al., 2008). According to Walsh et al. (2011), storm activity has increased at some locations in the North American Arctic, but there are no indications of systematic increases in storminess in the Arctic over the past half century, and no significant trend over the central Arctic in storm intensity has been found.

When evaluating published results, a problem in climatological cyclone analyses is that it is difficult to fully distinguish between true and apparent changes in cyclone occurrence and properties. Most studies rely on reanalysis data sets. The apparent changes may originate from changes in the amount, type and quality of observations assimilated into the reanalyses. Above all, the number of high latitude radiosonde sounding stations has decreased, but meanwhile the amount of satellite data has strongly increased. The results are also sensitive to the cyclone detection method applied (Neu et al., 2013). Several studies applying different reanalyses and cyclone detection methods have suggested an increase in Arctic cyclone activity. This is potentially partly related to sea ice decline, as the horizontal temperature gradient at the sea ice edge favours baroclinic instability, but interaction with lower latitudes cannot be ignored (Zhang et al., 2004; Trigo, 2006). On the basis of climate model experiments, Solomon (2006) concluded that a warmer climate with a greater water vapour concentration yields stronger extratropical cyclones. According to Bengtsson et al. (2006, 2009), however, the number of cyclones in the Arctic does not necessarily depend on the changes in greenhouse gas concentrations. Another challenge in evaluating the results is related to the terminology used. Some authors write about cyclones while others write about storms, and the criteria used (for instance, the lower threshold of wind speed for a system to be called storm) are often not mentioned. Given these uncertainties, results for cyclone climate in the Arctic should be treated carefully. Further research is necessary to fully understand the impact of the analysis problems discussed here on cyclone frequencies and intensities.

\subsection{Atmospheric transports of heat, moisture and aerosols}

Anomalous large-scale transports of atmospheric moisture have been shown to contribute to rapid sea ice melt events such as the 2007 record low sea ice extent. Increased air specific humidity and, above all, cloud cover, enhanced longwave downward radiation (Graversen et al., 2011), which supports melting of sea ice.

On a more general level, atmospheric transport of moist static energy from lower latitudes is the primary source of heat for the Arctic energy budget. Depending on the season, this heat transport across $70^{\circ} \mathrm{N}$ is equivalent to 60 $120 \mathrm{~W} \mathrm{~m}^{-2}$ if evenly distributed over the polar cap (Nakamura and Oort, 1988; Serreze et al., 2007a; Skific and Francis, 2013; Semmler et al., 2005; Serreze and Barry, 2005). It is weakest during April-May. On average, the annual lateral heat transport exceeds the downward solar radiation. For mass transport, the essential components are air moisture, clouds, and aerosols. The transport of latent heat is equivalent to $10-25 \mathrm{~W} \mathrm{~m}^{-2}$ (Serreze et al., 2007a). An indirect heating effect of moisture transport, via cloud formation and associated radiative effects, however, is much larger (see Sect. 4.3). Atmospheric heat transport has a strong effect, among others, on the interannual variability of the winter ice edge in the Bering and Barents seas, the areas where the ice edge has the most freedom to vary. Francis and Hunter (2007) showed that from 1979 to 2005 the Bering Sea ice edge was controlled mainly by anomalies in easterly winds associated with the Aleutian Low, whereas the Barents Sea ice edge was affected by anomalies in southerly wind, in addition to a major influence of sea surface temperature.

The transports of heat and moisture consist of the contributions by the background hemispheric circulation and by transient eddies. As an important part of the latter, synopticscale cyclones are responsible for most of the transport to the Arctic (e.g. Zhang et al., 2004). According to Jacobson and Vihma (2010) transient cyclones contribute $80-90 \%$ of the total meridional moisture flux. The main moisture flux into the Arctic occurs in the Norwegian Sea and Bering Strait sectors and the main moisture export in the Canadian sector. The interannual variability in moisture transport is mainly driven by variability in cyclone activity over the Greenland Sea and East Siberian Sea (Sorteberg and Walsh, 2008).

Considerable uncertainty remains in the vertical distribution of moisture transport. According to rawinsonde data, the 
meridional moisture flux across $70^{\circ} \mathrm{N}$ peaks approximately at the $850 \mathrm{hPa}$ level (Overland and Turet, 1994, Serreze et al., 1995), whereas according to the ERA-40 reanalysis the median peak level is at the $930 \mathrm{hPa}$ level during winter, and in other seasons is at the 970-990 hPa level (Jakobson and Vihma, 2010).

In addition to heat and moisture, large-scale atmospheric transport is the main contributor to the concentration and composition of cloud condensation nuclei. This is especially the case in winter (Garrett and Zhao, 2006). In summer over sea ice, aerosol concentrations in the boundary layer are generally low, but transport from lower latitudes may occur at higher elevations (Kupiszewski et al., 2013).

In general, little has been reported about trends in heat and moisture transport, although the effect of large transport on the September 2007 sea ice minimum has received attention (Graversen et al., 2011). The trends reported are very sensitive to the time period chosen. The ERA-40 reanalysis does not show any significant trend in the atmospheric moisture flux convergence over the Arctic Ocean during 1979-2001 (Serreze et al., 2006). Using satellite-based air temperatures and reanalysis products, Yang et al. (2010) detected periods of decreased and increased energy flux convergence in the Arctic: $25 \%$ of the cooling during a decade centred in the late 1980s was due to decreasing poleward energy transport, and half of the warming during a decade centred in the late 1990s was due to increasing poleward energy transport. Zhang et al. (2012) concluded that in the period 1948-2008 the net atmospheric moisture transport to the Arctic increased by $2.6 \%$ per decade. Modelling has suggested that poleward transport increases in a warmer climate. On the basis of sensitivity tests on the surface energy budget, Lu and Cai (2009) suggested an enhancement of poleward moist static energy transport, and Solomon (2006) found that stronger extra-tropical cyclones (Sect. 4.1) yielded increased northward heat and moisture transport.

Horizontal heat and moisture transports affect the sea ice cover via the radiative and turbulent heat fluxes. On the basis of ERA-Interim reanalysis, Maksimovich and Vihma (2012) calculated that an early melt onset in spring is favoured by a large downward long-wave radiation flux. This is typically associated with advection of warm and cloudy marine air masses from lower latitudes to the Arctic. Kapsch et al. (2013) reported that in years with an end-of-summer sea ice extent well below normal, a significantly enhanced transport of humid air was evident during the previous spring and was directed into the region where the ice retreat occurred. This enhanced transport of humid air led to an anomalous convergence of humidity and to an increased cloudiness, connected to increased long-wave downward radiation flux. Accordingly, the downwelling short-wave radiation was not decisive for the initiation of the melt, but rather acted as an amplifying factor later in the summer.

A further link between lower latitudes and Arctic climate change is seen in the atmospheric transport of sulphate aerosols (originating from burning of coal and oil) and black carbon (originating from combustion of diesel and biofuels) from anthropogenic sources into the Arctic. While sulphate aerosols are found to cool the atmosphere and surface due the increased net albedo, black carbon warms the air because of its increased absorption of solar radiation. Black carbon deposition on snow and ice may support melting due its reduced albedo (Sect. 3.5). During the past three decades, inflow of the cooling sulphate aerosols was reduced (Sharma et al., 2013), in contrast with an increased inflow of the warming black carbon (Serreze and Barrett, 2008). Shindell and Faluvegi (2009) estimate an aerosol contribution of $1.09 \pm 0.81{ }^{\circ} \mathrm{C}$ to the Arctic surface temperature increase between 1976-2007, based on a reconstruction of aerosol radiative forcing. Thus, an influence of those processes to Arctic warming appears likely, although uncertainties exist, concerning compensating effects and emissions of both warming and cooling aerosols.

Assessing the reported findings, the seasonal and largescale spatial variability in the transports of heat and moisture are reasonably well-known. Also, consistent results exist relating humidity transports to sea ice melt. Reliable detection of trends is, however, very difficult, because of (a) large interannual and decadal variability, and (b) inaccuracy of reanalyses, both due to model deficiencies and decadal differences in the amount of observations available. Considerable uncertainty remains, among others, in the vertical distribution of moisture transport. There are also large differences between reanalyses in the accuracy of the closure of the atmospheric moisture budget.

\subsection{Clouds, precipitation and evaporation}

Clouds occur in the Arctic due to local condensation and lateral advection from lower latitudes. The strong effect of clouds on the Arctic sea ice heat budget is reported in several studies (Francis et al., 2005; Francis and Hunter, 2007; Stroeve et al., 2007; Schweiger et al., 2008a, b; Lu and Cai, 2009; Graversen and Wang, 2009; Graversen et al., 2011). For most of the year the cloud radiative forcing is positive, i.e. clouds increase the downward long-wave radiation more than they reduce the downward short-wave radiation. In winter clouds may increase the downward long-wave radiation by up to $90 \mathrm{~W} \mathrm{~m}^{-2}$ (Overland and Guest, 1991; Minnet, 1999). On the basis of Russian drifting station data from 1968-1991, clouds significantly decrease the surface net radiation only in May-July (Chapman and Walsh, 1998), and on the basis of SHEBA data only in mid-summer (Intrieri et al., 2002; Shupe and Intrieri, 2004). The representativeness of these observations for the present Arctic climate is uncertain, because the cloud effect on net radiation is very sensitive to surface albedo, latitude, and cloud properties (Sedlar et al., 2011). The climatology of clouds and their properties are poorly known over the Arctic Ocean; though these are better known for circum-Arctic observatories, Shupe (2011). 
The radiative effects of clouds are very sensitive to the distribution of condensate content between liquid water and ice, warm liquid water clouds being much more effective in emitting long-wave radiation (Shupe and Intrieri, 2004). The reanalyses-based results of Maksimovich and Vihma (2012) and Kapsch et al. (2013) (Sect. 4.2) are in accordance with SHEBA data, suggesting that the cloud forcing on net radiation over the Arctic sea ice is still positive in spring and early summer, when the snowmelt on sea ice starts.

Excessive cloud cover in spring contributed to the September 2007 sea ice minimum (Graversen et al., 2011) whereas conclusions vary on the effects of the anomalously clear skies from June through August 2007, which resulted in increased downwelling short-wave radiation; according to Kay et al. (2008) it was a major factor in the Beaufort Sea, while according to Schweiger et al. (2008b) it did not substantially contribute to the sea ice minimum, based on observations in the Chukchi Sea.

Changes in the cloud cover in the marine Arctic are not well-known. Vihma et al. (2008) observed that the atmospheric transmissivity to short-wave radiation was significantly smaller during the Tara drift in April-September 2007 compared to Russian drifting stations in 1968-1990, suggesting an increase in cloud cover or optical thickness. Largely based on satellite data, Kay and Gettelman (2009) concluded that low cloud cover in early autumn has increased as a response to sea ice loss, but summer cloud cover does not depend on sea ice cover because of thermal decoupling. An increase in autumn cloud cover was also detected by Francis et al. (2009) and Palm et al. (2010). On the basis of synoptic observations reported from weather stations on land, drifting stations on sea ice, and ships, Eastman and Warren (2010) detected small positive pan-Arctic cloud cover trends in all seasons during the 1971-2009 period. Low clouds were primarily responsible for these trends. Focusing on the sea ice zone, clouds showed a tendency to increase with increasing air temperature and decreasing sea ice in all seasons except summer. Particularly in autumn, there was an increase in low clouds consistent with reduced sea ice, indicating that recent cloud changes may enhance the warming of the Arctic and accelerate the decline of sea ice (Eastman and Warren, 2010). On the basis of TOVS satellite data Schweiger et al. (2008a) observed that the sea ice retreat is linked to a decrease in lowlevel cloud amount and a simultaneous increase in mid-level clouds. The results on increasing cloud cover are consistent with the ensembles of 21st century projections by Vavrus et al. (2010), who found that clouds increased in autumn during periods of rapid sea ice loss.

It is noteworthy that the ERA-Interim reanalysis yields different cloud cover trends than observations: spring is the only season with significant trends in Arctic average cloudiness, and these trends are negative (Screen and Simmonds, 2010b). In general, the largest uncertainty and differences between different reanalysis data sets are related to the cloud depiction (Bromwich et al., 2007). Considering model exper- iments, Barton and Veron (2012) found that in the regional atmosphere model polar WRF (Weather Research and Forecasting) a low sea ice extent resulted in more clouds with larger liquid water paths.

It is difficult to quantify to what extent increases in air specific and relative humidity and cloud cover are due to sea ice decline or increased transports from lower latitudes. Recent studies have suggested increasing trends in the air moisture in the Arctic (Dee et al., 2011; Screen and Simmonds, 2010a, b; Rinke et al., 2009; Serreze et al., 2012). On the basis of three reanalyses (ERA-Interim, NASA-MERRA, and NCEP-CFSR) Serreze et al. (2012) detected significant increasing trends in vertically integrated water vapour content in the period 1979-2010, in particular in the regions where the sea ice cover decreased most and sea surface temperature increased most. Boisvert et al. (2013) studied evaporation from the Arctic Ocean and adjacent seas by applying a new method (Boisvert et al., 2012); the air specific humidity was calculated from satellite data (specifically, the Atmospheric Infrared Sounder onboard the EOS Aqua satellite) and the wind speed from the ERA-Interim reanalysis. Statistically significant seasonal decreasing trends in evaporation were found for December, January and February, because of the dominant effect of an increase in the $2 \mathrm{~m}$ air specific humidity that reduced the surface-air specific humidity difference in the Kara and Barents seas, the east Greenland Sea and the Baffin Bay region, where there is some open water yearround. Simultaneously, the evaporation slightly increased in the central Arctic, due to decreased sea ice concentration. The results of Boisvert et al. (2013) had both similarities and differences with those of Screen and Simmonds (2010a), based on in situ observations and ERA-Interim reanalysis. Screen and Simmonds (2010a) concluded that general increases in evaporation over the Arctic were occurring, but their study area did not include the Barents Sea, and their study period did not include November and December: according to Boisvert et al. (2013) this was probably the main reason for the different general trends.

Precipitation observations over Arctic land areas suggest that recent pan-Arctic precipitation exceeds the 1950s mean by about $5 \%$, and the years since 2000 have been wet both in terms of precipitation and river discharge (Walsh et al., 2011). According to Zhang et al. (2012), the Eurasian Arctic river discharge has increased by $1.8 \%$ per decade. This accelerated in the last decade, and an unprecedented, record high discharge occurred in 2007 (Shiklomanov and Lammers, 2009). The increasing trend has been attributed to warming effects, including intensifying precipitation minus evaporation, thawing permafrost, increasing greenness and reduced plant transpiration, but the causal physical processes have remained unclear (Zhang et al., 2012). These results are for Arctic land areas; information on temporal changes over the Arctic Ocean is almost entirely based on atmospheric reanalyses. In contrast to pan-Arctic land area findings, on the basis of the ERA-Interim analysis, Screen and 
Simmonds (2012) detected a decrease of total precipitation over the Arctic Ocean and Canadian Arctic Archipelago in 1989-2009. From the point of view of sea ice, it was more important that the summer snowfall decreased by $40 \%$ and the rain increased with a strong contribution to the recent decline (Sect. 3.5). Screen and Simmonds (2012) concluded that the decline in summer snowfall has likely contributed to the thinning of sea ice over recent decades. Contrary to findings by Screen and Simmonds (2012), experiments with a single regional atmospheric model by Porter et al. (2011) suggested that Arctic sea ice loss increases cloud cover, precipitation and evaporation in the Arctic.

In summary, clouds, precipitation, and evaporation are major factors affecting the state and change of the Arctic climate system, but large problems remain. First, a major problem in evaluating the changes is that there are very few surfacebased observations on clouds, precipitation and evaporation over the Arctic sea ice zone. Further, most cloud observations are qualitative, addressing the cloud coverage, levels, and types, which is not enough to estimate the radiative effects of clouds. Second, presentation of Arctic cloud physics, particularly for mixed-phase clouds, in reanalyses and climate models often causes large errors and uncertainties (e.g. Tjernström et al., 2008; Morrison et al., 2012).

\subsection{Vertical profile of Arctic warming}

Different results have been presented on the vertical structure of warming in the Arctic atmosphere. On the basis of the ECMWF ERA-40 reanalysis for 1979-2001, Graversen et al. (2008) detected the maximum warming well above the Earth's surface. They also found that in the summer half year a significant part of the vertical structure of warming is explained by an increase in the atmospheric energy transport from lower latitudes to the Arctic. On the basis of the ERA-Interim reanalysis for 1989-2008, Screen and Simmonds (2010b) found that the maximum Arctic warming occurred at the Earth's surface, and decreased with height in all seasons except summer. They further suggested that decreases in sea ice and snow cover here the dominant causes of the Arctic amplification. The different results of Graversen et al. (2008) and Screen and Simmonds (2010b) were related to different time periods, studied on the basis of different reanalyses. Later, on the basis of climate model experiments, Screen et al. (2012) suggested that local changes in sea ice concentration and sea surface temperature explain a large portion of the observed Arctic near-surface warming, whereas the majority of observed warming aloft is related to remote sea surface temperature changes, which have contributed to heating of the air masses that are transported from lower latitudes to the Arctic. According to Screen et al. (2012), the direct radiative forcing due to observed changes in greenhouse gases, ozone, aerosols, and solar output have been the primary contributors to Arctic tropospheric warming in summer.
Analyses of the vertical profile of Arctic warming have particular uncertainties. Recent studies have shown that, in the central Arctic, reanalyses have large errors in nearsurface variables (Lüpkes et al., 2010; Jakobson et al., 2012) and large mutual differences in the vertical structure at least up to the mid-troposphere (Chung et al., 2013). Possibilities to use other means to study the vertical profile of Arctic warming are limited. In situ observations over the Arctic Ocean are mostly restricted to the lowest tens of metres (buoys, ships). Radiosonde and tethersonde soundings have been made at ships and drifting ice stations, but most of these observations cover short periods only. An exception is the long-lasting radiosonde sounding program at the Russian ice stations from 1954 to 1991 (and to some extent also since 2003). The Russian drifting station data are an important basis for climatology of the vertical air temperature structure (e.g. Serreze et al., 1992) and, combined with shorter periods of data from more recent years, could be more systematically utilized to study the vertical structure of warming over the Arctic Ocean. Only a few studies of this kind have been carried out so far. Vihma et al. (2008) showed that, compared to the mean conditions in the Russian stations, summer 2007 was clearly warmer and more moist at altitudes from 200 to $1000 \mathrm{~m}$, although the July mean $2 \mathrm{~m}$ temperature had not increased at all. As long as the surface temperature is restricted by the melting point, the near-surface air temperatures over inner parts of large ice-covered areas cannot increase much above the melting point.

Satellite and surface (i.e. ship-, ice-, or land-) based remote sensing methods have the potential to provide better understanding of the vertical profile of air temperature trends over the Arctic Ocean. The time series of high-quality data are growing long enough to yield interesting results about interannual variations. For example, the Atmospheric Infrared Sounder has operated since 2003, and Devasthale et al. (2010) found that summer 2007 was 1.5 to $3.0 \mathrm{~K}$ warmer than the mean of 2003-2006, and 2008 in a thick layer from the surface up to the $400 \mathrm{hPa}$ level.

Despite the dominant warming trends, periodic cooling trends have also been detected in the Arctic. Focusing on the 1998-2011 period, Chung et al. (2013) demonstrated that four reanalysis products (ERA-Interim, CFSR, MERRA and NCEP II) showed a cooling trend in the Arctic mean $500 \mathrm{hPa}$ temperature in autumn, and this was supported by coastal rawinsonde data. No signs of recent near-surface cooling have been observed over the Arctic Ocean, but a widespread near-surface winter cooling has been observed over land areas in northern Eurasia and eastern North America since approximately 1988 (Cohen et al., 2012).

The ABL thickness, controlling the ABL heat capacity, is an important factor affecting the vertical structure of temperature trends in conditions of both warming and cooling. In the Arctic the shallower ABL, with a heat capacity smaller than at lower latitudes, contributes to the Arctic amplification (see Sect. 2). It may also partly explain the fact that 
the Arctic warming has been larger in winter than summer (e.g. Walsh et al., 2011) and that global warming has been larger during the night than during the day (Graversen and Wang, 2009; Esau et al., 2012). The stronger near-surface cooling of the Arctic compared to global temperatures during 1940-1970 (Chylek et al., 2009) may also have been affected by the smaller heat capacity of the thin ABL in the Arctic.

Studies of the vertical profile of Arctic climate change have benefitted from recent advances in understanding the mechanisms of stratosphere-troposphere coupling. It has been known for over a decade that a cold anomaly in the stratosphere typically results in a positive phase of both the AO and NAO (Wallace, 2000; Baldwin and Dunkerton, 2001; Karpechko and Manzini, 2012), and that stratospheric circulation influences the vertical wind shear near the tropopause. Consequently, the baroclinic instability across the depth of the troposphere changes, which affects the formation and growth of cyclones (Wittman et al., 2004). Recent advances in the field include studies demonstrating how disturbances in the Earth's surface, e.g. snow cover, generate vertically propagating planetary waves that reach the stratosphere and then have a lagged downward influence on the near-surface weather and climate (Cohen et al., 2007; Orsolini and Kvamstø, 2009; Allen and Zender, 2011; Peings and Magnusdottir, 2013). Bitz and Polvani (2012) found stratospheric ozone depletion warms the surface and the ocean to a depth of $1000 \mathrm{~m}$, and significantly reduces the sea ice extent.

\section{Recent advances in understanding the ocean's role in sea ice change}

The ocean's role in the Arctic climate system is the least explored, due to even greater inaccessibility compared to the Arctic atmosphere and sea ice. Mooring-based observations and ship-based expeditions during the IPY, as well as icetethered platforms and the first automatic underwater vehicles, have started to improve the situation, together with numerical process studies and climate change simulations.

The general picture of Arctic Ocean hydrology and circulations include a shallow surface layer of relatively fresh and cold water dominated by river runoff. The upper polar surface water largely isolates sea ice from the underlying warmer cores of salty Atlantic water between 300 and $500 \mathrm{~m}$ and relatively fresh Pacific water between 40 and $80 \mathrm{~m}$ depth (Bourgain and Gascard, 2012). The latter is largely limited to the Canadian Basin and adjacent seas.

In this section, we review recent progress in understanding the role of warm ocean inflow for sea ice change in conjunction with the ocean's part in ocean-sea ice-atmosphere feedbacks. While changes in ocean temperature and circulation are obvious, it appears more difficult to establish a link to sea ice changes.

\subsection{Transport and pathways of water}

The passages connecting the Arctic Ocean with the world ocean measure just several tens to hundreds of kilometres, in the cases of the Fram Strait, Bering Strait and Canadian Arctic Archipelago. The Barents Sea opening, with its $1000 \mathrm{~km}$ scale, is the exception. Pacific water enters the Arctic through the Bering Strait. The basic reason for the flow direction is a higher steric sea level in the Pacific compared to the Atlantic, giving rise to a wide trans-Arctic drift from the Bering Strait to the Fram Strait. In the Atlantic sector, the Canadian Arctic Archipelago is an export gateway for water volume and for freshwater (Rudels, 2012). The Fram Strait features southward transport of freshwater, salt and sea ice. The Canadian Arctic Archipelago carries about $50 \%$ of the freshwater transport of the Fram Strait (Dickson et al., 2007). Both the Fram Strait and Barents Sea opening experience northward transport of Atlantic water of equal magnitude. Recent high-resolution numerical flow simulations point to a volume inflow into the Arctic equally divided, but the heat entering the Arctic Ocean largely comes through the Fram Strait (Aksenov et al., 2010).

Pathways of northward ocean transports into the Fram Strait and Barents Sea opening are rather complex. Here we focus on the fate of the Atlantic water within the Arctic Ocean and its potential to impact sea ice. As a long known general feature of Fram Strait flow, the East Greenland Current flows southward while the West Spitsbergen Current (WSC) penetrates into the Arctic Ocean. This Atlantic water returns in parts $(2 \mathrm{~Sv})$, due to a local recirculation (Aagaard and Greisman, 1975; Marnela et al., 2013). The remaining part, ca 2-4 Sv (Schauer et al., 2008, and Beszcynska-Möller et al., 2012) of the WSC proceeds eastwards along the continental slope in two different branches (Schauer et al., 2004). Little is known about its further processing by turbulent eddies. Here we rely on high-resolution numerical models. Aksenov et al. (2010), using a numerical model of $1 / 12^{\circ}$ horizontal resolution, found that after passing the Fram Strait, the Atlantic water inflow splits into a deeper and a shallower branch following the shelf break of Svalbard, and then reunites east of the Yermak Plateau into a single Fram Strait branch.

An overall increase in northward flowing Fram Strait temperature and transports was found after 1999 and 2004 (Schauer et al., 2004, Dmitrenko et al., 2008, BeszcynskaMöller et al., 2012). An indication of increased inflow was already seen in the early 1990s when Atlantic water was observed in the southern Makarov Basin, which was previously dominated by Pacific waters (McLaughlin et al., 1996; Smith et al., 1999). Multi year pulse-like anomalies, which formed in the North Atlantic Ocean and Nordic Seas, have been observed passing the Fram Strait and further propagating eastwards along the Arctic continental slope. Mooringbased observations in the Fram Strait and oceanographic surveys during the DAMOCLES project, and earlier, gave an 
overall warming trend in the northward flowing Atlantic water of $0.06^{\circ} \mathrm{C}$ per year, between 1997 and 2010 (BeszcynskaMöller et al., 2012), although the actual warming trend in the northward WSC ceased after 2007, but was still elevated compared to the early 1990s. (Polyakov et al., 2011). On a longer timescale, proxy data from marine sediments off western Svalbard $\left(79^{\circ} \mathrm{N}\right)$ revealed that recent Atlantic water temperatures are unprecedented compared to the past 2000 years (Spielhagen et al., 2011). The volume transport variability in the WSC is limited to the offshore branch west of the Spitsbergen shelf, and no statistically significant trend can be found in the Arctic water volume transport.

\subsection{Northward heat transport}

Signals of increasing northward heat transport before 2007 can be traced along the Siberian shelf (Polyakov et al., 2008, 2011, Bourgain and Gascard, 2012) all the way to the Laptev slope (after 4.5-5 years), Chukchi shelf, and even the Lomonosov Ridge and the Makarov Basin (Rudels et al., 2013).

In the Eurasian and Makarov Basins, Arctic water warming of up to $1{ }^{\circ} \mathrm{C}$ was observed in 2007 relative to the 1990 s average (Polyakov et al., 2010). At the same time, the upper Arctic water layers were raised by up to $75-90 \mathrm{~m}$ in the central Arctic Ocean, related to a weakening of the Eurasian Basin upper-ocean stratification (Polyakov et al., 2010).

Even a seasonal cycle, originating from the Arctic water inflow at the Fram Strait, has been found to survive mixing processes and transformation into Arctic intermediate water (Ivanov et al., 2009). Integrated views based on mooring observations and high-resolution ocean models (Lique and Steele, 2012) show that the Arctic water seasonal cycle signal undergoes advection from the Fram Strait up to the St Anna Trough, and is then re-energized by the Barents Sea branch. The seasonal Arctic water temperature signal survives within the Nansen Basin. Interannual changes in the seasonal cycle amplitude can be as large as the mean seasonal cycle amplitude.

The observed interannual warming of Arctic water in the Arctic Ocean implies pools of anomalously low density. These are expected to slowly drain back south into the Nordic Seas (Karcher et al., 2011), with the anticipated effect of a reduced Denmark Strait overflow into the North Atlantic Ocean.

While ample progress has been made concerning the monitoring of the Arctic water inflow signal and understanding of its fate, the more difficult task of understanding the impact on sea ice coverage has just started to give results. It is hypothesized that the changes in the Eurasian Basin (warming and up-lifting of the Arctic water layer) facilitate greater upward transfer of Arctic water heat to the ocean surface layer, and thus impact ice melt (Polyakov et al., 2010).

\subsection{Links between ocean heat transport and sea ice melt}

Ocean heat transport into the Arctic is linked to the Atlantic Multidecadal Oscillation (AMO), both in observations (Chylek et al., 2009; Wood and Overland, 2010) and in climate model studies (e.g. Semenov, 2008). However, there is also an indication of increasing heat transport despite a recently reduced AMO (Koenigk and Brodeau, 2014). A general large-scale relationship between ocean northward heat transport in the Norwegian Sea and Arctic ice cover is considered to be well established (e.g. Sandø et al., 2010, Smedsrud et al., 2010).

It was long unclear to what extent processes connecting Atlantic water with ice melt could be described realistically. Despite strong surface cooling of inflowing Atlantic water into the Barents Sea, those waters warmed during the last 30 years by $0.3^{\circ} \mathrm{C}$ averaged over the Barents Sea. (Levitus et al., 2009). Recent findings in the area are often based on lengthening of pre-existing time series eventually enabling new conclusions. Already Vinje (2001) found that observed temperature anomalies in the central Norwegian Sea are significantly correlated with the Barents Sea sea ice extent with a lag of two years. Later, according to Årthun et al. (2012), observed sea ice reduction in the Barents sea (up to a mean of $50 \%$ on annually between 1998 and 2008) occurred concurrently with an increase in observed Atlantic heat transport due to both strengthening and warming of the inflow. The winter mean ice extent between 1979 and 1997 is clearly affected by the inflowing warm Arctic water, with an ice margin shifted towards the north and east (Årthun and Schrum, 2010).

Observation-based heat budget calculations by Årthun et al. (2012) show that the Barents Sea heat content, oceanatmosphere heat fluxes and sea ice cover respond on a monthly to annual timescale to increased heat transport from the Norwegian Sea. Barents Sea sea ice bottom heat uptake from the ocean is proportional to the water temperature (Rudels et al., 1999), and thus should have increased during the Barents Sea warming. On the annual average however, the ice bottom experiences freezing, while net melting occurs at the top. The Barents Sea sea ice cover is reduced by the warming water's capability to prevent freezing due to a longer period of cooling down water to the freezing point, especially in the central and eastern Barents Sea. Those relationships and lags are confirmed by a local ocean-sea ice circulation model (Årthun et al., 2012).

Coupled climate models often show a relation between northward ocean heat transport from the Nordic Seas into the Arctic Ocean and the Arctic sea ice cover. Holland et al. (2006) found pulse-like increases in ocean heat transport, leading ice melt events by a lag of 1-2 years, showing that rapid increases in heat transport can trigger ice melt events in models. Koenigk et al. (2011) found ice thickness to be highly negatively correlated with the ocean meridional over- 
turning circulation (MOC), due to larger than normal ocean heat transport to the north during periods of anomalously strong MOC. Bitz et al. (2006) even showed that positive heat transport events occurred independently of the ocean MOC. In such cases, the ocean heat transport events represent a positive feedback responding to reduced sea ice, increased brine release, strengthening convection and, in turn, bolstered the inflow of warm Atlantic water (Bitz et al., 2006). Koenigk et al. (2011) used a regional coupled climate model to find that enhanced surface heating in the Nordic Seas or North Atlantic contributes to increasing northward ocean heat transports in a future climate change projection.

Recent results, based on an ensemble of future climate projections with the EC-Earth GCM, suggest that heat transport through the Barents Sea opening governs sea ice variations in the Barents and Kara Sea on decadal timescales. Koenigk et al. (2012) have indicated that the increasing ocean heat transport strongly contributes to the reduced sea ice cover in the Barents and Kara Sea region, and thus hypothetically also contributes to the Arctic temperature amplification of the global climate warming (see Sect. 2.1). About $50 \%$ of the inflowing ocean heat anomaly in the 21 st century scenario ensemble is either used to melt sea ice or is passed to the atmosphere north of $70^{\circ} \mathrm{N}$.

Intense water mass transformation of the Atlantic inflow occurs not only in the Barents Sea, but also in the Kara Sea and Nansen Basin through atmosphere-ocean heat-exchange and ice edge processes (Årthun and Schrum 2010). Recent observations point to interaction processes along the shelf break north of Spitsbergen and in the Barents and Kara seas. In this area, the Atlantic water has the strongest potential to affect the sea ice. Temperature/Salinity ratio profiles at the Barents Sea shelf break lack a summer sub-surface temperature minimum between the warm summer surface and the warm Atlantic water layer. The Barents Sea shelf area is unique in the Arctic in having such conditions. This means that at this location, upward heat flow from the Atlantic water layer to the surface and the ice is likely (Rudels et al., 2013). The reasons behind this phenomenon are likely more intense vertical homogenization during winter, including deeper layers of Atlantic water. Rudels et al. (2013) related the homogenization to mechanical mixing processes due to wind and the topographic slope, which might increase the entrainment of Atlantic water into the surface layer.

\subsection{Pacific water inflow and sea ice melt}

The inflow of Pacific water through the Bering Strait is traditionally estimated at about $0.8 \mathrm{~Sv}$. (e.g. Coachman and Aagaard, 1988; Aagaard and Carmack, 1989) and confirmed later as the long-term annual mean (e.g. Woodgate and Aagaard, 2005). Strong seasonality in transport, temperature and salinity has been found (Woodgate and Aagaard, 2005).

Heat fluxes into the Arctic Ocean through the Bering Strait increased from 2001 to 2011 by a factor of 2 to a maximum of
$5 \times 10^{20} \mathrm{~J}$ per year, with peaks in 2007 and 2011 (Woodgate et al., 2010, 2012). The difference of the annual heat fluxes between 2001 and 2007 could melt $1.5 \times 10^{6} \mathrm{~km}^{2}$ of $1 \mathrm{~m}$ thick ice, corresponding to about one-third of the seasonal sea ice loss during the 2007 summer event.

The warming signal originating from the Bering Strait, propagated into the interior of the Canadian Basin during the mid and late 2000s, leading to a warming of the subsurface Pacific summer water between 1997 and 2008 (Bourgain and Gascard, 2012). A temperature increase in the Pacific layer below $40 \mathrm{~m}$ depth can potentially promote summer melt and reduce winter growth. Pacific summer water has been proposed to initially trigger the onset of seasonal sea ice bottom melt (Woodgate et al., 2010, 2012), and feed a winter time subsurface temperature maximum under the ice (Toole et al., 2010). This might contribute to sea ice retreat in the western Arctic. However, little is known about the mechanisms that actually bring the heat in contact with the ice. Entrainment of the Pacific summer water into the mixed layer has not been observed to our knowledge. Mixed layer studies instead tend to indicate ongoing isolation of the Pacific summer water from the mixed layer (Toole et al., 2010).

Better established is the role of the ocean in melting ice in response to local seasonal solar heating of the upper ocean. Summer insolation through leads and open water areas increases the sea surface temperature. Steele et al. (2008) found an upper ocean warming since the 1990 s with a maximum temperature of $5^{\circ} \mathrm{C}$ during summer 2007. Between 1979 and $2005,89 \%$ of the Arctic Ocean surface area experienced an increase in the solar energy absorption of up to $5 \%$ per year (Perovich and Polashenski, 2012).

In the Canadian Basin, solar-driven surface temperature increases are quickly isolated by freshwater from melting sea ice, so the heat remains between 25 and $35 \mathrm{~m}$. Contact with the surface can be re-established by wind induced vertical mixing, leading to melting at the ice edge and lead areas. Depending on the viability of the isolating freshwater layer, the sub-surface heat storage can contribute to winter ice melt or reduced winter ice freezing (Jackson et al., 2011).

\section{Integrative summary and prospects}

This article reviews recent progress in understanding the decline of Arctic sea ice. Ice cover has decreased since at least the 1970s, reflected in sea ice extent, thickness and volume. We are currently witnessing an Arctic sea ice pack that is thinning, becoming younger and more moveable, has a reducing albedo and lengthened melting season. All this makes the ice cover more susceptible to quickly responding to forcing from a warming earth system. Information on the mechanisms connected to the sea ice decline broadened during the 1990s, and huge knowledge gains were possible due to intensified efforts after the year 2000 when the sea ice reduction accelerated. Major contributions were made from the Inter- 
national Polar Year (IPY) and connected programs such as DAMOCLES and SEARCH. DAMOCLES studies on sea ice remote sensing are summarized in Heygster et al. (2012) and those on recent advance related to small-scale physical processes by Vihma et al. (2014).

The term "new Arctic" has been used to characterize a fundamental regime shift from predominantly multi year ice to enhanced fractions of seasonal and generally thinner ice. Sea ice erodes both from the top and from the bottom, forced by atmospheric warming, changes in circulation and transports, and by increased ocean heat transports especially in the Barents Sea. In the Atlantic sector, the relation of large-scale ocean heat transport and sea ice extent is well established. Direct forcing of the sea ice decline by the changing character of Pacific water inflow through the Bering Strait is unlikely to play a role. Instead, the increased rates of bottom melting in the Pacific sector are instead related to increased leads and associated ocean mixing.

Sea ice thickness has clearly decreased since the 1970s, from a winter mean estimate of $3.8 \mathrm{~m}$ down to $1.9 \mathrm{~m}$ in 2008. The relative decline of sea ice volume is even stronger due to simultaneous ice concentration reduction. Uncertainties of the sea ice volume trend estimates exist (about $-875 \pm 257 \mathrm{~km}^{3}$ per year in winter) due to sparse direct observations and poorly bounded assumptions of parameters needed for satellite signal interpretation.

Arctic sea ice cover variability is both internally generated (within the Arctic) and externally forced (by varying hemisphere scale conditions). The relative importance of those influences varies in time, and depends on the state of largescale atmospheric circulation. Northerly wind anomalies in the Atlantic sector of the Arctic support ice export and favour external control of the Arctic variability (i.e. small internally generated variability), likely due to hemisphere scale influences on the wind anomalies, which are forcing the ice export. Internally generated sea ice variability is particularly large during periods when the ice volume increases.

Sea ice drift velocities have increased since the 1950s, partly due to increasing wind speeds and partly due to reduced sea ice strength. Since 1989, interannual variability in ice drift speed appears to be connected to wind variability, while the trend in drift speed is related to ice thinning and a reduction in mechanical strength, which are both associated with transformation of multi year to first year ice.

Record low summer sea ice extents after the year 2000 delivered additional information on relevant mechanisms for the ice decline. The event in September 2007 commenced with increased poleward ice drift, partly in the form of first year ice. Anomalously high melt pond fractions were observed during the summers of 2007 and 2012, leading to reduced surface albedos. Increased convergence of meridional transport of moisture lead to reduced atmospheric short-wave transmissivity, enhanced cloud cover and intensified longwave radiative melting during summer 2007. That event also highlighted dynamic effects of a changed atmospheric circu- lation with enhanced meridional transport components. Pronounced CAI and DA anomalies during summer 2007 were responsible for increased ice transport, while the 2012 event occurred under comparatively regular atmospheric conditions, except for an anomalously strong summer storm in $\mathrm{Au}-$ gust.

Additional influences on the sea ice decline originate from a pronounced decline in summer snowfall, which has been observed since the late 1980s. Generally enhanced transport of humid air is found in spring of those years where the endof-summer sea ice extent is well below normal. Other observations accompanying the ice reduction are a longer melting period between melt onset in spring and the freeze-up in autumn. Black carbon deposition on sea ice more efficiently absorbs radiation for young sea ice, which enables stronger melting on the growing area of one year sea ice.

There are additional contributory factors important for explaining the sea ice decline, but either no signal can be detected, or results are inconclusive, or contradictory. While a northward shift of cyclone activity is undisputed, the systematic changes in cyclone intensity remain unclear due to strong temporal variability and changes in the amount and quality of in situ and remote sensing observations assimilated into atmospheric reanalyses. Further, comparison of individual studies is made difficult by the differences in terminology used and methodology applied, among others in the cyclone tracking algorithms. Scientific opinion diverges on the possibility to draw conclusions from observations. There are no clear indications of systematic increases in storminess in the Arctic over the past half century. Although large both in 2007 and 2012, the fraction of melt ponds does not show a statistically significant trend during the last few years or past decade. Considerable uncertainty exists in the moisture transport into the Arctic (among others, in its vertical distribution), strongly affecting the cloud radiative forcing of the sea ice cover.

Arctic temperatures have risen to a level likely unprecedented during the last 2000 years. The Arctic warming is enhanced by an Arctic amplification of the global warming signal, which is a result of the climate's internal response to changing radiative forcing. Arctic amplification is both supported by the sea ice reduction and is at the same time accelerating the ice decline. In addition to the long anticipated sea ice-albedo feedback, cloud and water vapour feedbacks, both combined temperature feedback (lapse rate and Planck) and atmospheric circulation feedbacks play a role. The amplitude of the feedback depends on the state of the Arctic, its sea ice cover and planetary boundary layer stability. An emerging Arctic amplification of global warming by, for example, the sea ice-albedo feedback can regionally activate and strengthen additional feedbacks such as the water vapour feedback with the result of an enhanced Arctic amplification. Consistent with this, increasing trends in vertically integrated water vapour content have been found, particularly in the regions where the sea ice cover has decreased most and sea 
surface temperature has increased most, leading to a locally enhanced tropospheric warming. According to observations, low cloud coverage has increased particularly in autumn, but also to a lesser extent in other seasons. The reasons for the increase are not clear. Sea ice decline itself favours evaporation but, according to Boisvert et al. (2013), winter evaporation in the marine Arctic decreased in 2003-2011, and according to Schweiger et al. (2008a) sea ice decline is linked to a decrease in low cloud amount. These apparent contradictions may be explained by the competing effects of decreased sea ice cover and increased advection of moist, cloudy air masses to the Arctic.

Reasonable concepts explaining the Arctic amplification exist, although quantitative understanding is lacking. The different feedback mechanisms involved in the shaping of Arctic amplification depend on, and partly compensate for, each other in a self-adjusting way, if single feedback types are suppressed. This suggests an Arctic amplification which is robust and not dependent on individual mechanisms.

Atmosphere, sea ice and ocean processes interact in nonlinear ways on various scales under global climate forcing. The Arctic sea ice extent shows a trend towards less ice, superimposed by oscillations reflecting the various influences. Each record low sea ice extent is followed by a partial recovery. Consulting climate change projections, even decadal scale periods of records lows can potentially alternate with periods of at least partially recovered sea ice (e.g. Massonnet et al., 2012). The recent and distinct recovery of summer sea ice extent in September 2013 might provide an insight on the range of variability that might be expected during the coming decades. It also illustrates a debate on the possible tipping point for the sea ice cover.

Model studies of different complexity agree on a return of the sea ice cover under conditions of reducing climate forcing, e.g. reduced greenhouse gas concentrations (Tietsche et al., 2011; Stranne and Björk, 2012). In that sense, a tipping point of no immediate return does not exist. If the atmospheric forcing changes trends, sea ice can be re-established within just a few years. However, there is ample indication for a point of increased destabilization of the ice which justifies the term "new Arctic". The decrease of extent, thickness and volume distinctly accelerated around the year 2000. Positive feedbacks due to reduced sea ice and snow albedo are clearly detectable, often with a stronger amplitude after the millennium shift. This accelerated development is further supported by the increasing prevalence of thinner and younger ice, which is more susceptible to further atmospheric warming and associated circulation changes, and even more sensitive to the albedo effects of soot deposition.
Climate prediction is an emerging science branch, still very much unexplored, but with well-founded hopes. Predictability studies with climate models indicate that sea ice anomalies can potentially persist for several years (Holland et al., 2011, Koenigk et al., 2009; Tietsche et al., 2013), a situation which allows for potential predictive skill of both sea ice and atmospheric conditions at least on a multi year average. Potential predictability on multi year timescales is high for the Arctic due to decadal scale ocean variability and due to signal storage capability in sea ice and ocean. Note that the potential predictability refers to climate conditions as simulated by climate models, typically under-representing the complexity of processes. Ongoing and upcoming projects (e.g. SPECS and the CMIP6 decadal prediction experiments) promise rapid knowledge gains on the real-world potential. Current retro-active prediction experiments provide good predictability for the Arctic area (Doblas-Reyes, 2013)

On the down side for predictability prospects is the thinning of the sea ice, which possibly reduces predictability due to lower signal storage capacity in the ice and increased interannual variability. It is unknown to what extent this can be compensated by heat anomalies stored in the ocean. Predictability in marginal ice areas, such as the Labrador Sea and the Barents Sea, are clearly influenced by largely predictable oscillations in ocean circulation and heat transports. A careful development of the future prospect of Arctic climate predictability requires accurate observation of Arctic ocean layers periodically in contact with the atmosphere, both for understanding storage processes and for a precise initialization of predictions. Furthermore, better understanding of the processes (including stratosphere-troposphere interactions) that control the evolution of atmospheric large-scale circulation will be essential for understanding the real potential of Arctic climate prediction.

For a proper exploration of climate prediction, it is essential to understand drivers and describe feedbacks of Arctic predictability. Studies such as those reviewed here are therefore key, not only to describe Arctic climate change, but also for providing process understanding that is properly reflected in prediction systems. A challenge in practical prediction efforts is an appropriate initialization of the ocean state, including Arctic sea ice concentration, thickness and ocean temperature. This requires access to observations and exploration of initialization techniques. Also from that initialization point of view, further observations of the state of the Arctic are essential. 
Acknowledgements. First of all, we thank all researchers we were able to refer to for this review, for their most valuable research contributions. We see a huge knowledge gain since the start of the IPY which coincides with a qualitative change in the Arctic. The valuable findings cited here would not be possible without the field campaigns, drifting ice buoys, moorings, numerical models, unmanned underwater and aerial technologies, as well as satellite-based exploration, which all have intensified during the last decade. We also greatly thank Jean-Claude Gascard, who initiated this work as a part of his commitment to the DAMOCLES project and its aftermath. Three reviewers pointed us to weak points of the original manuscript, so we could improve the paper. Support was also provided by the Swedish Meteorological and Hydrological Institute (SMHI), the Swedish ADSIMNOR project funded by the Swedish research council FORMAS and the Academy of Finland (contract 259537).

Edited by: K. Dethloff

\section{References}

Aagaard, K. and Carmack, E. C.: The role of sea ice and other fresh water in the Arctic circulation, J. Geophys. Res., 94, 1448514498, 1989.

Aagaard, K. and Greisman, P.: Toward new mass and heat budgets for the Arctic Ocean, J. Geophys. Res., 80, 3821-3827, 1975.

Aksenov, Y., Bacon, S., Coward, A. C., and Nurser, A. J.: The North Atlantic inflow to the Arctic Ocean: High-resolution model study, J. Marine Syst., 79, 1-22, 2010.

Allen, R. J. and Zender, C. S.: Forcing of the Arctic Oscillation by Eurasian snow cover, J. Clim., 24, 6528-6539, 2011.

Amundrud, T. L., Melling, H., Ingram, R. G., and Allen, S. E.: The effect of structural porosity on the ablation of sea ice ridges, J. Geophys. Res.-Oceans, 111, 1978-2012, 2006.

Armstrong, A. E., Tremblay, L. B., and L. A. Mysak: A data-model intercomparison study of Arctic sea-ice variability, Clim. Dyn., 20, 465-476, doi:10.1007/s00382-002-0284-2, 2003.

Arrhenius, S.: XXXI. On the influence of carbonic acid in the air upon the temperature of the ground, The London, Edinburgh, and Dublin Philosophical Magazine and Journal of Science, 41, 237276, 1896.

Årthun, M. and Schrum, C.: Ocean surface heat flux variability in the Barents Sea, J. Marine Syst., 83, 88-98, 2010.

Årthun, M., Eldevik, T., Smedsrud, L. H., Skagseth, Ø., and Ingvaldsen, R. B.: Quantifying the influence of atlantic heat on barents sea ice variability and retreat*, J. Climate, 25, 4736-4743, 2012.

Baldwin, M. P. and Dunkerton, T. J.: Stratospheric harbingers of anomalous weather regimes, Science, 294, 581-584, doi:10.1126/science.1063315, 2001.

Barton, N. P. and Veron, D. E.: Response of clouds and surface energy fluxes to changes in sea-ice cover over the Laptev Sea (Arctic Ocean), Clim. Res., 54, 69-84, doi:10.3354/cr01101, 2012.

Bengtsson, L., Semenov, V. A., and Johannessen, O. M.: The early twentieth-century warming in the Arctic - a possible mechanism, J. Climate, 17, 4045-4057, 2004.

Bengtsson, L., Hodges, K. I., and Roeckner, E.: Storm tracks and climate change, J. Climate, 19, 3518-3543, 2006.
Bengtsson, L., Hodges, K. I., and Keenlyside, N.: Will extratropical storms intensify in a warmer climate?, J. Climate, 22, 22762301, 2009.

Beszczynska-Möller, A., Fahrbach, E., Schauer, U., and Hansen, E.: Variability in Atlantic water temperature and transport at the entrance to the Arctic Ocean, 1997-2010, ICES J. Mar. Sci., 69, 852-863, 2012.

Bitz, C. M. and Polvani, L. M.: Antarctic climate response to stratospheric ozone depletion in a fine resolution ocean climate model, Geophys. Res. Lett., 39, L20705, doi:10.1029/2012GL053393, 2012.

Bitz, C. M., Gent, P. R., Woodgate, R. A., Holland, M. M., and Lindsay, R.: The influence of sea ice on ocean heat uptake in response to increasing $\mathrm{CO}_{2}$, J. Climate, 19, 2437-2450, doi:10.1175/JCLI3756.1, 2006.

Blanchard-Wrigglesworth, E., Armour, K. C., Bitz, C. M., and DeWeaver, E.: Persistence and inherent predictability of Arctic sea ice in a GCM ensemble and observations, J. Climate, 24, 231-250, 2011.

Boisvert, L. N., Markus, T., Parkinson, C. L., and Vihma, T.: Moisture fluxes derived from EOS aqua satellite data for the north water polynya over 2003-2009, J. Geophys. Res.-Atmos., 117, D06119, doi:10.1029/2011JD016949, 2012.

Boisvert, L. N., Markus, T., and Vihma, T.: Moisture flux changes and trends for the entire Arctic in 2003-2011 derived from EOS Aqua data, J. Geophys. Res.-Oceans, 118, 5829-5843, doi:10.1002/jgrc.20414, 2013.

Boer, G. and Yu, B.: Climate sensitivity and response, Clim. Dynam., 20, 415-429, 2003.

Bourgain, P. and Gascard, J. C.: The Atlantic and summer Pacific waters variability in the Arctic Ocean from 1997 to 2008, Geophys. Res. Lett., 39, L05603, doi:10.1029/2012GL051045, 2012.

Bourke, R. H. and Garrett, R. P.: Sea ice thickness distribution in the Arctic Ocean, Cold Reg. Sci. Technol., 13, 259-280, doi:10.1016/0165-232X(87)90007-3, ISSN 0165-232X, 1987.

Bromwich, D. H., Fogt, R. L., Hodges, K. I., and Walsh, J. E.: A tropospheric assessment of the ERA-40, NCEP, and JRA-25 global reanalyses in the polar regions, J. Geophys. Res.-Atmos., 112, D10111, doi:10.1029/2006JD007859, 2007.

Broecker, W. S.: Floating glacial ice caps in the Arctic Ocean, Science, 188, 1116-1118, doi:10.1126/science.188.4193.1116, 1975.

Brucker, L., Cavalieri, D. J., Markus, T., and Ivanoff, A.: NASA Team 2 Sea Ice Concentration Algorithm Retrieval Uncertainty, IEEE T. Geosci. Remote, 52, 11, 7336-7352, doi:10.1109/TGRS.2014.2311376, 2014.

Chung, C. E., Cha, H., Vihma, T., Räisänen, P., and Decremer, D.: On the possibilities to use atmospheric reanalyses to evaluate the warming structure in the Arctic, Atmos. Chem. Phys., 13, 1120911219, doi:10.5194/acp-13-11209-2013, 2013.

Chylek, P., Folland, C. K., Lesins, G., Dubey, M. K., and Wang, M.: Arctic air temperature change amplification and the Atlantic Multidecadal Oscillation, Geophys. Res. Lett., 36, L14801, doi:10.1029/2009GL038777, 2009.

Clarke, A. D. and Noone, K. J.: Soot in the Arctic snowpack: a cause for perturbations in radiative transfer. Atmos. Environ., 19, 2045-2053, 1985. 
Coachman, L. K. and Aagaard, K.: Transports through Bering Strait: Annual and interannual variability, J. Geophys. Res., 93, 15535-15539, doi:10.1029/JC093iC12p15535, 1988.

Cohen, J., Barlow, M., Kushner, P. J., and Saito, K.: Stratosphere-Troposphere Coupling and Links with Eurasian Land Surface Variability, J. Climate, 20, 5335-5343. doi:10.1175/2007JCLI1725.1, 2007.

Cohen, J. L., Furtado, J. C., Barlow, M. A., Alexeev, V. A., and Cherry, J. E.: Arctic warming, increasing snow cover and widespread boreal winter cooling, Environ. Res. Lett., 7, 014007 , doi:10.1088/1748-9326/7/1/014007, 2012.

Comiso, J. C.: Abrupt decline in the Arctic winter sea ice cover, Geophys. Res. Lett., 33, L18504, doi:10.1029/2006GL027341, 2006.

Comiso, J. C., Parkinson, C. L., Gersten, R., and Stock, L.: Accelerated decline in the Arctic sea ice cover, Geophys. Res. Lett., 35, L01703, doi:10.1029/2007GL031972, 2008.

Crook, J. A., Forster, P. M., and Stuber, N.: Spatial Patterns of Modeled Climate Feedback and Contributions to Temperature Response and Polar Amplification, J. Climate, 24, 3575-3592, doi:10.1175/2011JCLI3863.1, 2011.

Cuzzone, J. and Vavrus, S.: The relationships between Arctic sea ice and cloud-related variables in the ERA-Interim reanalysis and CCSM3, Environ. Res. Lett., 6, 014016, doi:10.1088/17489326/6/1/014016, 2011.

Dee, D. P., Uppala, S. M., Simmons, A. J., Berrisford, P., Poli, P., Kobayashi, S., Andrae, U., Balmaseda, M. A., Balsamo, G., Bauer, P., Bechtold, P., Beljaars, A. C. M., van de Berg, L., Bidlot, J., Bormann, N., Delsol, C., Dragani, R., Fuentes, M., Geer, A. J., Haimberger, L., Healy, S. B., Hersbach, H., Hólm, E. V., Isaksen, L., Kållberg, P., Köhler, M., Matricardi, M., McNally, A. P., Monge-Sanz, B. M., Morcrette, J. J., Park, B. K., Peubey, C., de Rosnay, P., Tavolato, C., Thépaut, J. N., and Vitart, F.: The ERA-Interim reanalysis: configuration and performance of the data assimilation system, Q. J. Roy. Meteor. Soc., 137, 553-597, 2011.

Deser, C. and Teng, H.: Evolution of Arctic sea ice concentration trends and the role of atmospheric circulation forcing, 1979-2007, Geophys. Res. Lett., 35, L02504, doi:10.1029/2007GL032023, 2008.

Devasthale, A., Willén, U., Karlsson, K.-G., and Jones, C. G.: Quantifying the clear-sky temperature inversion frequency and strength over the Arctic Ocean during summer and winter seasons from AIRS profiles, Atmos. Chem. Phys., 10, 5565-5572, doi:10.5194/acp-10-5565-2010, 2010.

Dickson, R., Rudels, B., Dye, S., Karcher, M., Meincke, J., and Yashayaev, I.: Current estimates of freshwater flux through Arctic and subarctic seas, Prog. Oceanogr., 73, 210-230, 2007.

Dmitrenko, I. A., Polyakov, I. V., Kirillov, S. A., Timokhov, L. A., Frolov, I. E., Sokolov, V. T., Simmons, H. L., Ivanov, V. V., and Walsh, D.: Toward a warmer Arctic Ocean: spreading of the early 21 st century, Atlantic Water warm anomaly along the Eurasian Basin margins, J. Geophys. Res., 113, C05023, doi:10.1029/2007JC004158, 2008.

Doblas-Reyes, F. J., Andreu-Burillo, I., Chikamoto, Y., GarcíaSerrano, J., Guemas, V., Kimoto, M., Mochizuki, T., Rodrigues, L. R. L., Van Oldenborgh, G. J.: Initialized near-term regional climate change prediction, Nature communications, 4, 1715, doi:10.1038/ncomms2704, 2013.
Dorn, W., Dethloff, K., and Rinke, A.: Limitations of a coupled regional climate model in the reproduction of the observed Arctic sea-ice retreat, The Cryosphere, 6, 985-998, doi:10.5194/tc-6985-2012, 2012.

Döscher, R. and Koenigk, T.: Arctic rapid sea ice loss events in regional coupled climate scenario experiments, Ocean Sci., 9, 217 248, doi:10.5194/os-9-217-2013, 2013.

Döscher, R., Wyser, K., Meier, H. M., Qian, M., and Redler, R.: Quantifying Arctic contributions to climate predictability in a regional coupled ocean-ice-atmosphere model, Clim. Dynam., 34, 1157-1176, 2010.

Eastman, R. and Warren, S. G.: Interannual variations of arctic cloud types in relation to sea ice, J. Climate, 23, 1286-1303, 2010.

Esau, I., Davy, R., and Outten, S.: Complementary explanation of temperature response in the lower atmosphere, Environ. Res. Lett., 7, 044026, doi:10.1088/1748-9326/7/4/044026, 2012.

Flocco, D., Schroeder, D., Feltham, D. L., and Hunke, E. C.: Impact of melt ponds on Arctic sea ice simulations from 1990 to 2007, J. Geophys. Res., 117, C09032, doi:10.1029/2012JC008195, 2012.

Francis, J. A. and Hunter, E.: Drivers of declining sea ice in the Arctic winter: a tale of two seas, Geophys. Res. Lett., 34, L17503, doi:10.1029/2007GL030995, 2007.

Francis, J. A., Hunter, E., Key, J. R., and Wang, X.: Clues to variability in Arctic minimum sea ice extent, Geophys. Res. Lett., 32, L21501, doi:10.1029/2005GL024376, 2005.

Francis, J. A., Chan, W., Leathers, D. J., Miller, J. R., and Veron, D. E.: Winter Northern Hemisphere weather patterns remember summer Arctic sea-ice extent, Geophys. Res. Lett., 36, L07503, doi:10.1029/2009GL037274, 2009.

Frey, K. E., Perovich, D. K., and Light, B.: The spatial distribution of solar radiation under a melting Arctic sea ice cover, Geophys. Res. Lett., 38, L22501, doi:10.1029/2011GL049421, 2011.

Garrett, T. J. and Zhao, C.: Increased Arctic cloud longwave emissivity associated with pollution from mid-latitudes, Nature, 440 , 787-789, 2006.

Gascard, J. C., Festy, J., le Goff, H., Weber, M., Bruemmer, B., Offermann, M., and Bottenheim, J.: Exploring Arctic transpolar drift during dramatic sea ice retreat, EOS T. Am. Geophys. Un., 89, 21-22, 2008.

Gerland, S. and Haas, C.: Snow-depth observations by adventurers traveling on Arctic sea ice, Ann. Glaciol., 52, 369-376, doi:10.3189/172756411795931552, 2011

Gerdes, R.: Atmospheric response to changes in Arctic sea ice thickness, Geophys. Res. Lett., 33, L18709, doi:10.1029/2006GL027146, 2006.

Gillett, N. P., Stone, D. A., Stott, P. A., Nozawa, T., Karpechko, A. Y., Hegerl, G. C., Wehner, M. F., and Jones, P. D. Attribution of polar warming to human influence, Nat. Geosci., 1, 750-754, 2008.

Gimbert, F., Jourdain, N. C., Marsan, D., Weiss, J., and Barnier, B.: Recent mechanical weakening of the Arctic sea ice cover as revealed from larger inertial oscillations, J. Geophys. Res., 117, C00J12, doi:10.1029/2011JC007633, 2012.

Graversen, R. G. and Wang, M.: Polar amplification in a coupled climate model with locked albedo, Clim. Dynam., 33, 629-643, 2009. 
Graversen, R. G., Mauritsen, T., Tjernström, M., Källén, E., and Svensson, G.: Vertical structure of recent Arctic warming, Nature, 451, 53-56, 2008.

Graversen, R. G., Mauritsen, T., Drijfhout, S., Tjernström, M., and Mårtensson, S.: Warm winds from the Pacific caused extensive Arctic sea-ice melt in summer 2007, Clim. Dynam., 36, 21032112, 2011.

Grenfell, T. C., Light, B., and Sturm, M.: Spatial distribution and radiative effects of soot in the snow and sea ice during the SHEBA experiment, J. Geophys. Res., 107, 8032, doi:10.1029/2000JC000414, 2002.

Hansen, J. and Nazarenko, L.: Soot climate forcing via snow and ice albedos, P. Natl. Acad. Sci. USA, 101, 423-428, doi:10.1073/pnas.2237157100, 2004.

Hansen, J., Sato, M. K. I., Ruedy, R., Nazarenko, L., Lacis, A., Schmidt, G. A., and Zhang, S.: Efficacy of climate forcings, J. Geophys. Res.-Atmos., 110, D18104, doi:10.1029/2005JD005776, 2005.

Häkkinen, S., Proshutinsky, A., and Ashik, I.: Sea ice drift in the Arctic since the 1950s, Geophys. Res. Lett., 35, L19704, doi:10.1029/2008GL034791, 2008.

Heygster, G., Alexandrov, V., Dybkjær, G., von HoyningenHuene, W., Girard-Ardhuin, F., Katsev, I. L., Kokhanovsky, A., Lavergne, T., Malinka, A. V., Melsheimer, C., Toudal Pedersen, L., Prikhach, A. S., Saldo, R., Tonboe, R., Wiebe, H., and Zege, E. P.: Remote sensing of sea ice: advances during the DAMOCLES project, The Cryosphere, 6, 1411-1434, doi:10.5194/tc-61411-2012, 2012.

Hodson, D. L. R., Keeley, S. P. E., West, A., Ridley, J., Hawkins, E., and Hewitt, H. T.: Identifying uncertainties in Arctic climate change projections, Clim. Dynam., 40, 2849-2865, doi:10.1007/s00382-012-1512-z, 2013.

Hilmer, M. and Jung, T.: Evidence for a recent change in the link between the North Atlantic Oscillation and Arctic sea ice export, Geophys. Res. Lett., 27, 989-992, 2000.

Holland, M. M., Bitz, C. M., and Tremblay, B.: Future abrupt reductions in the summer Arctic sea ice, Geophys. Res. Lett., 33, L23503, doi:10.1029/2006GL028024, 2006.

Holland, M. M., Serreze, M. C., and Stroeve, J.: The sea ice mass budget of the Arctic and its future change as simulated by coupled climate models, Clim. Dynam., 34, 185-200, 2010.

Holland, M. M., Bailey, D. A., and Vavrus, S.: Inherent sea ice predictability in the rapidly changing Arctic environment of the Community Climate System Model, version 3, Clim. Dynam., 36, 1239-1253, 2011.

Holland, M. M., Bailey, D. A., Briegleb, B. P., Light, B., and Hunke, E.: Improved sea ice shortwave radiation physics in CCSM4: the impact of melt ponds and aerosols on Arctic sea ice*, J. Climate, 25, 1413-1430, 2012.

Hutchings, J. K. and Rigor, I. G.: Role of ice dynamics in anomalous ice conditions in the Beaufort Sea during 2006 and 2007, J. Geophys. Res., 117, C00E04, doi:10.1029/2011JC007182, 2012.

Intrieri, J. M., Fairall, C. W., Shupe, M. D., Persson, P. O. G., Andreas, E. L., Guest, P. S., and Moritz, R. E.: An annual cycle of Arctic surface cloud forcing at SHEBA, J. Geophys. Res., 107, 8039, doi:10.1029/2000JC000439, 2002.

Inoue, J. and Kikuchi, T.: Outflow of summertime Arctic sea ice observed by ice drifting buoys and its linkage with ice reduction and atmospheric circulation patterns, J. Meteorol. Soc. Jpn., 85, 881-887, 2007.

Ivanov, V. V., Polyakov, I. V., Dmitrenko, I. A., Hansen, E., Repina, I. A., Kirillov, S. A., and Timokhov, L. A.: Seasonal variability in Atlantic water off Spitsbergen, Deep-Sea Res. Pt. I, 56, $1-14,2009$.

Jackson, J. M., Allen, S. E., McLaughlin, F. A., Woodgate, R. A., and Carmack, E. C.: Changes to the near-surface waters in the Canada Basin, Arctic Ocean from 1993-2009: a basin in transition, J. Geophys. Res., 116, C10008, doi:10.1029/2011JC007069, 2011.

Jakobson, E. and Vihma, T.: Atmospheric moisture budget in the Arctic based on the ERA-40 reanalysis, Int. J. Climatol., 30, 2175-2194, 2010.

Jakobson, E., Vihma, T., Palo, T., Jakobson, L., Keernik, H., and Jaagus, J.: Validation of atmospheric reanalyzes over the central Arctic Ocean, Geophys. Res. Lett. 39, L10802, doi:10.1029/2012GL051591, 2012.

Johannessen, O. M., Bengtsson, L., Miles, M. W., Kuzmina, S. I., Semenov, V. A., Alekseev, G. V., Nagurnyi, A. P., Zakharov, V. F., Bobylev, L. P., Pettersson, L. H., Hasselmann, K., and Cattle, H. P.: Arctic climate change: observed and modelled temperature and sea-ice variability, Tellus A, 56, 328-341, doi:10.1111/j.1600-0870.2004.00060.x, 2004.

Jung, T., Hilmer, M., Ruprecht, E., Kleppek, S., Gulev, S. K., and Zolina, O.: Characteristics of the Recent Eastward Shift of Interannual NAO Variability, J. Climate, 16, 3371-3382, doi:10.1175/1520-0442(2003)016<3371:COTRES> 2.0.CO;2, 2003.

Jungclaus, J. H. and Koenigk, T.: Low-frequency variability of the Arctic climate: The role of oceanic and atmospheric heat transport variations, Clim. Dyn., 34, 265-279, doi:10.1007/s00382009-0569-9, 2010.

Kaleschke, L., Lüpkes, C., Vihma, T., Haarpaintner, J., Bochert, A., Hartmann, J., and Heygster, G.: SSM/I Sea Ice Remote Sensing for Mesoscale Ocean-Atmosphere Interaction Analysis, Can. J. Remote Sensing, 27, 526-537, 2001.

Kapsch, M. L., Graversen, R. G., and Tjernström, M.: Springtime atmospheric energy transport and the control of Arctic summer sea-ice extent, Nature Climate Change, 3, 744-748, doi:10.1038/nclimate1884, 2013.

Karlsson, J. and Svensson, G.: Consequences of poor representation of Arctic sea-ice albedo and cloud-radiation interactions in the CMIP5 model ensemble, Geophys. Res. Lett., 40, 4374-4379, doi:10.1002/grl.50768, 2013.

Karcher, M., Beszczynska-Möller, A., Kauker, F., Gerdes, R., Heyen, S., Rudels, B., and Schauer, U.: Arctic Ocean warming and its consequences for the Denmark Strait overflow, J. Geophys. Res.-Oceans, 116, C02037, doi:10.1029/2010JC006265, 2011.

Karpechko, A. Y. and Manzini, E.: Stratospheric influence on tropospheric climate change in the Northern Hemisphere, J. Geophys. Res., 117, D05133, doi:10.1029/2011JD017036, 2012.

Kattsov, V. M., Ryabinin, V. E., Overland, J. E., Serreze, M. C., Visbeck, M., Walsh, J. E., Meier, W., and Zhang, X.: Arctic seaice change: a grand challenge of climate science, J. Glaciol., 56, 1115-1121, doi10.3189/002214311796406176, 2010.

Kaufman, D. S., Schneider, D. P., McKay, N. P., Ammann, C. M., Bradley, R. S., Briffa, K. R., and Vinther, B. M.: Recent warm- 
ing reverses long-term Arctic cooling, Science, 325, 1236-1239, doi:10.1126/science.1173983, 2009.

Kay, J. E. and Gettelman, A.: Cloud influence on and response to seasonal Arctic sea ice loss, J. Geophys. Res.-Atmos., 114, D18204, doi:10.1029/2009JD011773, 2009.

Kay, J. E. and L'Ecuyer, T.: Observational constraints on Arctic Ocean clouds and radiative fluxesduring the early 21 st century, J. Geophys. Res.-Atmos., 118, 7219-7236, 2013.

Kay, J. E., L'Ecuyer, T., Gettelman, A., Stephens, G., and O'Dell, C.: The contribution of cloud and radiation anomalies to the 2007 Arctic sea ice extent minimum, Geophys. Res. Lett., 35, L08503, doi:10.1029/2008GL033451, 2008.

Koenigk, T. and Brodeau, L.: Ocean heat transport into the Arctic in the twentieth and twenty-first century in EC-Earth, Clim. Dynam., 42, 3101-3120, doi:10.1007/s00382-013-1821-x, 2014.

Koenigk, T., Mikolajewicz, U., Haak, H., and Jungclaus, J.: Variability of Fram Strait sea ice export: causes, impacts and feedbacks in a coupled climate model, Clim. Dynam., 26, 17-34, 2006.

Koenigk, T., Mikolajewicz, U., Jungclaus, J. H., and Kroll, A.: Sea ice in the Barents Sea: seasonal to interannual variability and climate feedbacks in a global coupled model, Clim. Dynam., 32, 1119-1138, 2009.

Koenigk, T., Döscher, R., and Nikulin, G.: Arctic future scenario experiments with a coupled regional climate model, Tellus A, 63, 69-86, doi:10.1111/j.1600-0870.2010.00474.x, 2011.

Koenigk, T., Beatty, C. K., Caian, M., Döscher, R., and Wyser, K.: Potential decadal predictability and its sensitivity to sea ice albedo parameterization in a global coupled model, Clim. Dynam., 38, 2389-2408, 2012.

Koenigk, T., Devasthale, A., and Karlsson, K.-G.: Summer Arctic sea ice albedo in CMIP5 models, Atmos. Chem. Phys., 14, 19871998, doi:10.5194/acp-14-1987-2014, 2014.

Kolstad, E. W. and Bracegirdle, T. J.: Marine cold-air outbreaks in the future: an assessment of IPCC AR4 model results for the Northern Hemisphere, Clim. Dynam., 30, 871-885, 2008.

Kupiszewski, P., Leck, C., Tjernström, M., Sjogren, S., Sedlar, J., Graus, M., Müller, M., Brooks, B., Swietlicki, E., Norris, S., and Hansel, A.: Vertical profiling of aerosol particles and trace gases over the central Arctic Ocean during summer, Atmos. Chem. Phys., 13, 12405-12431, doi:10.5194/acp-13-12405-2013, 2013.

Kurtz, N. T., Markus, T., Farrell, S. L., Worthen, D. L., and Boisvert, L. N.: Observations of recent Arctic sea ice volume loss and its impact on oceanatmosphere energy exchange and ice production, J. Geophys. Res., 116, C04015, doi:10.1029/2010JC006235, 2011.

Kwok, R.: Outflow of Arctic Ocean sea ice into the Greenland and Barents Seas: 1979-2007, J. Climate, 22, 2438-2457, 2009.

Kwok, R. and Rothrock, D. A.: Decline in Arctic sea ice thickness from submarine and ICESat records: 1958-2008, Geophys. Res. Lett., 36, L15501, doi:10.1029/2009GL039035, 2009.

Kwok, R., Cunningham, G. F., Wensnahan, M., Rigor, I., Zwally, H. J., and Yi, D.: Thinning and volume loss of the Arctic Ocean sea ice cover: 2003-2008, J. Geophys. Res., 114, C07005, doi:10.1029/2009JC005312, 2009.

Kwok, R., Spreen, G., and Pang, S.: Arctic sea ice circulation and drift speed: Decadal trends and ocean currents, J. Geophys. Res.Oceans, 118, 2408-2425, doi:10.1002/jgrc.20191, 2013.
Laine, V.: Arctic sea ice regional albedo variability and trends, 1982-1998, J. Geophys. Res.-Oceans, 109, C06027, doi:10.1029/2003JC001818, 2004.

Langen, P. L. and Alexeev, V. A.: Polar amplification as a preferred response in an idealized aquaplanet GCM, Clim. Dynam., 29, 305-317, 2007.

Langen, P. L., Graversen, R. G., and Mauritsen, T.: Separation of contributions from radiative feedbacks to polar amplification on an aquaplanet, J. Climate, 25, 3010-3024, 2012.

Laxon, S., Peacock, N., and Smith, D.: High interannual variability of sea ice thickness in the Arctic region, Nature, 425, 947-950, 2003.

Laxon, S. W., Giles, K. A., Ridout, A. L., Wingham, D. J., Willatt, R., Cullen, R., Kwok, R., Schweiger, A., Zhang, J., Haas, C., Hendricks, S., Krishfield, R., Kurtz, N., Farrell, S., and Davidson, M.: CryoSat-2 estimates of Arctic sea ice thickness and volume, Geophys. Res. Lett., 40, 732-737, doi:10.1002/grl.50193, 2013.

Lean, J. and Rind, D.: Climate forcing by changing solar radiation, J. Climate, 11, 3069-3094, 1998.

Levitus, S., Antonov, J. I., Boyer, T. P., Locarnini, R. A., Garcia, H. E., and Mishonov, A. V.: Global ocean heat content 19552008 in light of recently revealed instrumentation problems, Geophys. Res. Lett., 36, L07608, doi:10.1029/2008GL037155, 2009.

Lindsay, R. W. and Zhang, J.: The thinning of Arctic sea ice, 19882003: have we passed a tipping point?, J. Climate, 18, 48794894, 2005.

Lique, C. and Steele, M.: Where can we find a seasonal cycle of the Atlantic water temperature within the Arctic Basin?, J. Geophys. Res.-Oceans, 117, C03026, doi:10.1029/2011JC007612, 2012.

Liu, Y., Key, J. R., and Wang, X.: Influence of changes in sea ice concentration and cloud cover on recent Arctic surface temperature trends, Geophys. Res. Lett., 36, L20710, doi:10.1029/2009GL040708, 2009.

Lu, J. and Cai, M.: Seasonality of polar surface warming amplification in climate simulations, Geophys. Res. Lett., 36, L16704, doi:10.1029/2009GL040133, 2009.

Lüpkes, C., Vihma, T., Jakobson, E., König-Langlo, G., and Tetzlaff, A.: Meteorological observations from ship cruises during summer to the central Arctic: a comparison with reanalysis data, Geophys. Res. Lett., 37, L09810, doi:10.1029/2010GL042724, 2010.

Maksimovich, E.: L'impact des Conditions Météorologiques sur la Variabilité de Démarrage de la Fonte sur la Glace de Mer en Arctique centrale, $\mathrm{PhD}$ thesis, University Pierre et Marie Curie, Laboratory LOCEAN, Paris, 2012.

Maksimovich, E. and Vihma, T.: The effect of surface heat fluxes on interannual variability in the spring onset of snow melt in the central Arctic Ocean, J. Geophys. Res., 117, C07012, doi:10.1029/2011JC007220, 2012.

Manabe, S. and Wetherald, R. T.: The effects of doubling the $\mathrm{CO}_{2}$ concentration on the climate of a general circulation modell, J. Atmos. Sci., 32, 3-15, 1975.

Marks, A. A. and King, M. D.: The effects of additional black carbon on the albedo of Arctic sea ice: variation with sea ice type and snow cover, The Cryosphere, 7, 1193-1204, doi:10.5194/tc7-1193-2013, 2013. 
Markus, T., Stroeve, J. C., and Miller, J.: Recent changes in Arctic sea ice melt onset, freezeup, and melt season length, J. Geophys. Res., 114, C12024, doi:10.1029/2009JC005436, 2009.

Marnela, M., Rudels, B., Houssais, M.-N., Beszczynska-Möller, A., and Eriksson, P. B.: Recirculation in the Fram Strait and transports of water in and north of the Fram Strait derived from CTD data, Ocean Sci., 9, 499-519, doi:10.5194/os-9-499-2013, 2013.

Maslanik, J. A., Fowler, C., Stroeve, J., Drobot, S., Zwally, J., Yi, D., and Emery, W.: A younger, thinner Arctic ice cover: increased potential for rapid, extensive sea-ice loss, Geophys. Res. Lett., 34, L24501, doi:10.1029/2007GL032043, 2007.

Maslanik, J., Stroeve, J., Fowler, C., and Emery, W.: Distribution and trends in Arctic sea ice age through spring 2011, Geophys. Res. Lett., 38, L13502, doi:10.1029/2011GL047735, 2011.

Massonnet, F., Fichefet, T., Goosse, H., Bitz, C. M., PhilipponBerthier, G., Holland, M. M., and Barriat, P.-Y.: Constraining projections of summer Arctic sea ice, The Cryosphere, 6, 13831394, doi:10.5194/tc-6-1383-2012, 2012.

McCabe, G. J., Clark, M. P., and Serreze, M. C.: Trends in Northern Hemisphere Surface Cyclone Frequency and Intensity, J. Climate, 14, 2763-2768, doi:10.1175/15200442(2001)014<2763:TINHSC> 2.0.CO;2, 2001.

McLaughlin, F. A., Carmack, E. C., Macdonald, R. W., and Bishop, J. K. B.: Physical and geochemical properties across the Atlantic/Pacific water mass front in the southern Canadian Basin, J. Geophys. Res., 101, 1183-1197, doi:10.1029/95JC02634, 1996.

Meier, W. N., Stroeve, J., Barrett, A., and Fetterer, F.: A simple approach to providing a more consistent Arctic sea ice extent time series from the 1950s to present, The Cryosphere, 6, 13591368, doi:10.5194/tc-6-1359-2012, 2012.

Meier, W. N., Gallaher, D., and Campbell, G. G.: New estimates of Arctic and Antarctic sea ice extent during September 1964 from recovered Nimbus I satellite imagery, The Cryosphere, 7, 699705, doi:10.5194/tc-7-699-2013, 2013.

Meier, W. N., Hovelsrud, G. K., van Oort, B. E. H., Key, J. R., Kovacs, K. M., Michel, C., Haas, C., Granskog, M. A., Gerland, S., Perovich, D. K., Makshtas, A., and Reist, J. D.: Arctic sea ice in transformation: A review of recent observed changes and impacts on biology and human activity, Rev. Geophys., 52, 185217, doi:10.1002/2013RG000431, 2014.

Melling, H.: Sea ice of the northern Canadian Arctic Archipelago, J. Geophys. Res., 107, 3181, doi:10.1029/2001JC001102, 2002.

Mesquita, M. D. S., Atkinson, D. E., and Hodges, K. I.: Characteristics and variability of storm tracks in the North Pacific, Bering Sea, and Alaska, J. Climate, 23, 294-311, 2010.

Min, S.-K., Zhang, X., Zwiers, F. W., and Agnew, T.: Human influence on Arctic sea ice detectable from early 1990s onwards, Geophys. Res. Lett., 35, L21701, doi:10.1029/2008GL035725, 2008.

Minnett, P. J.: The influence of solar zenith angle and cloud type on cloud radiative forcing at the surface in the Arctic, J. Climate, 12, 147-158, 1999.

Mikolajewicz, U., Sein, D. V., Jacob, D., Koenigk, T., Podzun, R., and Semmler, T.: Simulating Arctic sea ice variability with a coupled regional atmosphere-ocean-sea ice model, Meteorol. Z., 14, 793-800, doi:10.1127/0941-2948/2005/0083, 2005.

Morrison, H., de Boer, G., Feingold, G., Harrington, J., Shupe, M. D., and Sulia, K.: Resilience of persistent Arctic mixed-phase clouds, Nature Geosci., 5, 11-17, doi:10.1038/NGE01332, 2012.
Nakamura, N. and Oort, A. H.: Atmospheric heat budgets of the polar regions, J. Geophys. Res., 93, 9510-9524, 1988.

Neu, U., Akperov, M. G., Bellenbaum, N., Benestad, R., Blender, R., Caballero, R., and Wernli, H.: IMILAST: a community effort to intercompare extratropical cyclone detection and tracking algorithms, B. Am. Meteorol. Soc., 94, 529-547, 2013.

Nilsson, A. and Döscher, R.: Signals from a noisy region, in: When the Ice Breaks: Media and the Politics of Arctic Climate Change, edited by: Christensen, M., Nilsson, A., and Wormbs, N., PalgraveMcMillan, New York, ISBN:9781137266224, 2013.

Nghiem, S. V., Rigor, I. G., Perovich, D. K., Clemente-Colón, P., Weatherly, J. W., and Neumann, G.: Rapid reduction of Arctic perennial sea ice, Geophys. Res. Lett., 34, L19504, doi:10.1029/2007GL031138, 2007.

Notz, D.: The future of ice sheets and sea ice: between reversible retreat and unstoppable loss, P. Natl. Acad. Sci. USA, 106, 2059020595, 2009.

Notz, D. and Marotzke, J.: Observations reveal external driver for Arctic sea-ice retreat, Geophys. Res. Lett., 39, L08502, doi:10.1029/2012GL051094, 2012.

Orsolini, Y. J. and Kvamst $\varnothing$, N. G.: Role of Eurasian snow cover in wintertime circulation: decadal simulations forced with satellite observations, J. Geophys. Res., 114, D19108, doi:10.1029/2009JD012253, 2009.

Overland, J. E. and Guest, P. S.: The Arctic snow and air temperature budget over sea ice during winter, J. Geophys. Res. 96, 4651-4662, 1991.

Overland, J. E. and Turet, P.: Variability of the atmospheric energy flux across $70 \mathrm{~N}$ computed from the GFDL data set, The polar Oceans and Their Role in Shaping the Global Environment, 313325, doi:10.1029/GM085p0313, 1994.

Overland, J. E. and Wang, M.: Large-scale atmospheric circulation changes are associated with the recent loss of Arctic sea ice, Tellus A, 62, 1-9, 2010.

Overland, J. E., Wood, K. R., and Wang, M.: Warm Arctic-cold continents: climate impacts of the newly open Arctic Sea, Polar Res., 30, 15787, doi:10.3402/polar.v30i0.15787, 2011.

Palm, S. P., Strey, S. T., Sphinhirne, J., and Markus, T.: Influence of Arctic sea ice extent on polar cloud fraction and vertical structure and implications for regional climate, J. Geophys. Res., 115, D21209, doi:10.1029/2010JD013900, 2010.

Parkinson, C. L. and Cavalieri, D. J.: Arctic sea ice variability and trends, 1979-2006, J. Geophys. Res., 113, C07003, doi:10.1029/2007JC004558, 2008.

Parkinson, C. L. and Cavalieri, D. J.: Antarctic sea ice variability and trends, 1979-2010, The Cryosphere, 6, 871-880, doi:10.5194/tc-6-871-2012, 2012.

Peings, Y. and Magnusdottir, G.: Response of the wintertime Northern Hemisphere atmospheric circulation to current and projected Arctic sea ice decline: a numerical study with CAM5, J. Climate, 27, 244-264, doi:10.1175/JCLI-D-13-00272.1, 2013.

Perovich, D. K. and Richter-Menge, J. A.: From points to poles: extrapolating point measurements of sea-ice mass balance, Ann. Glaciol., 44, 188-192, 2006.

Perovich, D. K., Grenfell, T. C., Light, B., and Hobbs, P. V.: Seasonal evolution of the albedo of multiyear Arctic sea ice, J. Geophys. Res., 107, 8044, doi:10.1029/2000JC000438, 2002.

Perovich, D. K., Light, B., Eicken, H., Jones, K. F., Runciman, K., and Nghiem, S. V.: Increasing solar heating of the Arc- 
tic Ocean and adjacent seas, 1979-2005: Attribution and role in the ice-albedo feedback, Geophys. Res. Lett., 34, L19505, doi:10.1029/2007GL031480, 2007a.

Perovich, D. K., Nghiem, S. V., Markus, T., and Schweiger, A.: Seasonal evolution and interannual variability of the local solar energy absorbed by the Arctic sea ice-ocean system, J. Geophys. Res., 112, C03005, doi:10.1029/2006JC003558, $2007 \mathrm{~b}$.

Perovich, D. K., Richter-Menge, J. A., Jones, K. F., and Light, B.: Sunlight, water, and ice: extreme Arctic sea ice melt during the summer of 2007, Geophys. Res. Lett., 35, L11501, doi:10.1029/2008GL034007, 2008.

Perovich, D. K., Jones, K. F., Light, B., Eicken, H., Markus, T., Stroeve, J., and Lindsay, R.: Solar partitioning in a changing Arctic sea-ice cover, Ann. Glaciol., 52, 192-196, 2011.

Perovich, D. K. and Polashenski, C.: Albedo evolution of seasonal Arctic sea ice, Geophys. Res. Lett., 39, L08501, doi:10.1029/2012GL051432, 2012.

Persson, P. O. G., Fairall, C. W., Andreas, E. L., Guest, P. S., and Perovich, D. K.: Measurements near the Atmospheric Surface Flux Group tower at SHEBA: near-surface conditions and surface energy budget, J. Geophys. Res.-Oceans, 107, 8045, doi:10.1029/2000JC000705, 2002.

Pithan, F. and Mauritsen, T.: Arctic amplification dominated by temperature feedbacks in contemporary climate models, Nature Geoscience, 7, 181-184, doi:10.1038/ngeo2071, 2014.

Polyakov, I. V., Alexeev, V. A., Belchansky, G. I., Dmitrenko, I. A., Ivanov, V. V., Kirillov, S. A., and Yashayaev, I.: Arctic Ocean freshwater changes over the past 100 years and their causes, J. Climate, 21, 364-384, 2008.

Polyakov, I. V., Timokhov, L. A., Alexeev, V. A., Bacon, S., Dmitrenko, I. A., Fortier, L., and Toole, J.: Arctic ocean warming contributes to reduced polar ice cap, J. Phys. Oceanogr., 40, 2743-2756, 2010.

Polyakov, I. V., Alexeev, V. A., Ashik, I. M., Bacon, S., Beszczynska-Möller, A., Carmack, E. C., and Woodgate, R.: Fate of early 2000s Arctic warm water pulse, B. Am. Meteorol. Soc., 92, 561-566, 2011.

Polyakov, I. V., Walsh, J, E., and Kwok, R.: Recent changes of arctic multiyear sea ice coverage and the likely causes, B. Am. Meteorol. Soc., 93, 145-151, doi:10.1175/BAMS-D-11-00070.1, 2012.

Porter, D. F., Cassano, J. J., and Serreze, M. C.: Analysis of the Arctic atmospheric energy budget in WRF: a comparison with reanalyses and satellite observations, J. Geophys. Res., 116, D22108, doi:10.1029/2011JD016622, 2011.

Radionov, V. F., Bryazgin, N. N., and Alexandrov, E. I.: The Snow Cover of the Arctic Basin (No. APL-UW-TR-9701), Washington Univ., Applied Physics Lab., Seattle, 1997.

Rampal, P., Weiss, J., and Marsan, D.: Positive trend in the mean speed and deformation rate of Arctic sea ice, 1979-2007, J. Geophys. Res., 114, C05013; doi:10.1029/2008JC005066, 2009.

Rayner, N. A., Brohan, P., Parker, D. E., Folland, C. K., Kennedy, J. J., Vanicek, M., Ansell, T., and Tett, S. F. B.: Improved analyses of changes and uncertainties in sea surface temperature measured in situ since the mid-nineteenth century: the HadSST2 data set, J. Climate, 19, 446-469, 2006.

Rigor, I. G., Wallace, J. M., and Colony, R. L.: Response of Sea Ice to the Arctic Oscillation. J. Climate, 15, 2648-2663. doi:10.1175/1520-0442(2002)015<2648:ROSITT>2.0.CO;2, 2002.
Riihelä, A., Manninen, T., and Laine, V.: Observed changes in the albedo of the Arctic sea-ice zone for the period 1982-2009, Nature Climate Change, 3, 895-898, doi:10.1038/nclimate1963, 2013.

Rinke, A., Melsheimer, C., Dethloff, K., and Heygster, G.: Arctic total water vapor: comparison of regional climate simulations with observations, and simulated decadal trends, J. Hydrometeorol., 10, 113-129, 2009.

Roeckner, E., Mauritsen, T., Esch, M., and Brokopf, R.: Impact of melt ponds on Arctic sea ice in past and future climates as simulated by MPI-ESM, J. Adv. Model. Earth Syst., 4, M00A02, doi:10.1029/2012MS000157, 2012.

Rothrock, D. A. and Zhang, J.: Arctic Ocean sea ice volume: what explains its recent depletion?, J. Geophys. Res.-Oceans, 110, C01002, doi:10.1029/2004JC002282, 2005.

Rothrock, D. A., Percival, D. B., and Wensnahan, M.: The decline in arctic sea-ice thickness: separating the spatial, annual, and interannual variability in a quarter century of submarine data, J. Geophys. Res., 113, C05003, doi:10.1029/2007JC004252, 2008.

Rösel, A. and Kaleschke, L.: Exceptional melt pond occurrence in the years 2007 and 2011 on the Arctic sea ice revealed from MODIS satellite data, J. Geophys. Res., 117, C05018, doi:10.1029/2011JC007869, 2012.

Rudels, B.: Arctic Ocean circulation and variability - advection and external forcing encounter constraints and local processes, Ocean Sci., 8, 261-286, doi:10.5194/os-8-261-2012, 2012.

Rudels, B., Friedrich, H., Hainbucher, D., and Lohmann, G.: On the parameterisation of oceanic sensible heat loss to the atmosphere and to ice in an ice-covered mixed layer in winter, Deep-Sea Res. Pt. II, 46, 1385-1425, 1999.

Rudels, B., Schauer, U., Björk, G., Korhonen, M., Pisarev, S., Rabe, B., and Wisotzki, A.: Observations of water masses and circulation with focus on the Eurasian Basin of the Arctic Ocean from the 1990 s to the late 2000s, Ocean Sci., 9, 147-169, doi:10.5194/os-9-147-2013, 2013.

Sandø, A. B., Nilsen, J. E. Ø., Gao, Y., and Lohmann, K.: Importance of heat transport and local air-sea heat fluxes for Barents Sea climate variability, J. Geophys. Res., 115, C07013, doi:10.1029/2009JC005884, 2010.

Schauer, U., Fahrbach, E., Osterhus, S., and Rohardt, G.: Arctic warming through the Fram Strait: oceanic heat transport from 3 years of measurements, J. Geophys. Res.-Oceans, 109, C06026, doi:10.1029/2003JC001823, 2004.

Schauer, U., Beszczynska-Möller, A., Walczowski, W., Fahrbach, E., Piechura, J., and Hansen, E.: Variation of measured heat flow through the Fram Strait between 1997 and 2006, in: Arctic-Subarctic Ocean Fluxes, Springer Netherlands, 65-85, 2008.

Schweiger, A. J., Lindsay, R. W., Vavrus, S., and Francis, J. A.: Relationships between Arctic Sea Ice and Clouds during Autumn, J. Climate, 21, 4799-4810, doi:10.1175/2008JCLI2156.1, 2008a.

Schweiger, A. J., Zhang, J., Lindsay, R. W., and Steele, M.: Did unusually sunny skies help drive the record sea ice minimum of 2007?, Geophys. Res. Lett., 35, L10503, doi:10.1029/2008GL033463, 2008b.

Schweiger, A., Lindsay, R., Zhang, J., Steele, M., Stern, H., and Kwok, R.: Uncertainty in modeled Arctic sea ice volume, J. Geophys. Res., 116, C00D06, doi:10.1029/2011JC007084, 2011. 
Screen, J. A. and Simmonds, I.: Increasing fall-winter energy loss from the Arctic Ocean and its role in Arctic temperature amplification, Geophys. Res. Lett., 37, L16797, doi:10.1029/2010GL044136, 2010a.

Screen, J. A. and Simmonds, I.: The central role of diminishing sea ice in recent Arctic temperature amplification, Nature, 464, 1334-1337, 2010b.

Screen, J. A. and Simmonds, I.: Declining summer snowfall in the Arctic: causes, impacts and feedbacks, Clim. Dynam., 38, 22432256, 2012.

Screen, J. A., Simmonds, I., and Keay, K.: Dramatic interannual changes of perennial Arctic sea ice linked to abnormal summer storm activity, J. Geophys. Res., 116, D15105, doi:10.1029/2011JD015847, 2011.

Screen, J. A., Deser, C., and Simmonds, I.: Local and remote controls on observed Arctic warming, Geophys. Res. Lett., 39, L10709, doi:10.1029/2012GL051598, 2012.

Sedlar, J., Tjernström, M., Mauritsen, T., Shupe, M. D., Brooks, I. M., Persson, P. O. G., and Nicolaus, M.: A transitioning Arctic surface energy budget: the impacts of solar zenith angle, surface albedo and cloud radiative forcing, Clim. Dynam., 37, 1643-1660, doi:10.1007/s00382-010-0937-5, 2011.

Semenov, V. A.: Influence of oceanic inflow to the Barents Sea on climate variability in the Arctic region, Dokl. Earth Sci., 418, 91-94, 2008.

Semmler, T., Jacob, D., Schlünzen, K. H., and Podzun, R.: The water and energy budget of the Arctic atmosphere, J. Climate, 18, 2515-2530, 2005.

Sepp, M. and Jaagus, J.: Changes in the activity and tracks of Arctic cyclones, Climatic Change, 105, 577-595, 2011.

Serreze, M. C. and Barrett, A. P.: The summer cyclone maximum over the central Arctic Ocean, J. Climate, 21, 1048-1065, doi:10.1175/2007JCLI1810.1, 2008.

Serreze, M. C. and Barry, R. G.: The Arctic Climate System, Cambridge University Press, Cambridge, 385 pp., 2005.

Serreze, M. C. and Barry, R. G.: Processes and impacts of Arctic amplification: a research synthesis, Global Planet. Change, 77, 85-96, 2011.

Serreze, M. C., Kahl, J. D., and Schnell, R. C.: Low-level Temperature Inversions of the Eurasian Arctic and Comparisons with Soviet Drifting Station Data, J. Climate 5, 599-613, 1992.

Serreze, M. C., Box, J. E., Barry, R. G., and Walsh, J. E.: Characteristics of Arctic synoptic activity, 1952-1989, Meteor. Atmos. Phys., 51, 147-164, 1993.

Serreze, M. C., Barry, R. G., Rehder, M. C., and Walsh, J. E.: Variability in atmospheric circulation and moisture flux over the arctic, Philos. T. Roy. Soc. A, 352, 215-225, doi:10.1098/rsta.1995.0065, 1995.

Serreze, M. C., Barrett, A. P., Slater, A. G., Woodgate, R. A., Aagaard, K., Lammers, R. B., Steele, M., Moritz, R., Meredith, M., and Lee, C. M.: The large-scale freshwater cycle of the Arctic, J. Geophys. Res.-Oceans, 111, C11010, 0148-0227, doi:10.1029/2005JC003424, 2006.

Serreze, M. C., Barrett, A. P., Slater, A. G., Steele, M., Zhang, J., and Trenberth, K. E.: The large-scale energy budget of the Arctic, J. Geophys. Res., 112, D11122, doi:10.1029/2006JD008230, $2007 \mathrm{a}$.
Serreze, M. C., Holland, M. M., and Stroeve, J.: Perspectives on the Arctic's shrinking sea-ice cover, Science, 315, 1533-1536, 2007b.

Serreze, M. C., Barrett, A. P., Stroeve, J. C., Kindig, D. N., and Holland, M. M.: The emergence of surface-based Arctic amplification, The Cryosphere, 3, 11-19, doi:10.5194/tc-3-11-2009, 2009.

Serreze, M. C., Barrett, A. P., and Stroeve, J.: Recent changes in tropospheric water vapor over the Arctic as assessed from radiosondes and atmospheric reanalyses. J. Geophys. Res.-Atmos., 117, D10104, doi:10.1029/2011JD017421, 2012.

Sharma, S., Ishizawa, M., Chan, D., Lavoué, D., Andrews, E., Eleftheriadis, K., and Maksyutov, S.: 16-year simulation of Arctic black carbon: transport, source contribution, and sensitivity analysis on deposition, J. Geophys. Res.-Atmos., 118, 943-964, doi:10.1029/2012JD017774, 2013.

Shiklomanov, A. I. and Lammers, R. B.: Record Russian river discharge in 2007 and the limits of analysis, Environ. Res. Lett., 4, 045015, doi:10.1088/1748-9326/4/4/045015, 2009.

Shindell, D. and Faluvegi, G.: Climate response to regional radiative forcing during the twentieth century, Nat. Geosci., 2, 294-300, doi:10.1038/ngeo473, 2009.

Shupe, M. D.: Clouds at arctic observatories, Part II: Thermodynamic phase characteristics, J. Appl. Meteorol. Clim., 50, 645661, doi:10.1175/2010JAMC2468.1, 2011.

Shupe, M. D. and Intrieri, J. M.: Cloud radiative forcing of the arctic surface: the influence of cloud properties, surface albedo, and solar zenith angle, J. Climate, 17, 616-628, 2004.

Simmonds, I. and Keay, K.: Extraordinary september Arctic sea ice reductions and their relationships with storm behavior over 1979-2008, Geophys. Res. Lett., 36, L19715, doi:10.1029/2009GL039810, 2009.

Simmonds, I. and Rudeva, I.: The great arctic cyclone of August 2012, Geophys. Res. Lett., 39, L23709, doi:10.1029/2012GL054259, 2012.

Skeie, P.: Meridional flow variability over the Nordic seas in the Arctic Oscillation framework, Geophys. Res. Lett., 27, 25692572, doi:10.1029/2000GL011529, 2000.

Skific, N. and Francis, J. A.: Drivers of projected change in arctic moist static energy transport, J. Geophys. Res.-Atmos., 118, 2748-2761, doi:10.1002/jgrd.50292, 2013.

Smedsrud, L. H., Ingvaldsen, R., Nilsen, J. E. Ø., and Skagseth, Ø.: Heat in the Barents Sea: transport, storage, and surface fluxes, Ocean Sci., 6, 219-234, doi:10.5194/os-6-219-2010, 2010.

Smith, J. N., Ellis, K. M., and Boyd, T.: Circulation features in the central Arctic Ocean revealed by nuclear fuel reprocessing tracers from Scientific Ice Expeditions 1995 and 1996, J. Geophys. Res., 104, 29663-29677, doi:10.1029/1999JC900244, 1999.

Soden, B. J., Held, I. M., Colman, R., Shell, K. M., Kiehl, J. T., and Shields, C. A.: Quantifying climate feedbacks using radiative kernels, J. Climate, 21, 3504-3520, 2008.

Solomon, A.: Impact of latent heat release on polar climate, Geophys. Res. Lett., 33, L07716, doi:10.1029/2005GL025607, 2006.

Sorteberg, A. and Walsh, J. E.: Seasonal cyclone variability at $70^{\circ} \mathrm{N}$ and its impact on moisture transport into the Arctic, Tellus A, 60, 570-586, 2008.

Spielhagen, R. F., Werner, K., Sørensen, S. A., Zamelczyk, K., Kandiano, E., Budeus, G., and Hald, M.: Enhanced modern heat transfer to the Arctic by warm Atlantic water, Science, 331, 450453, 2011. 
Spreen, G., Kern, S., Stammer, D., and Hansen, E.: Fram Strait sea ice volume export estimated between 2003 and 2008 from satellite data, Geophys. Res. Lett., 36, L19502, doi:10.1029/2009GL039591, 2009.

Spreen, G., Kwok, R., and Menemenlis, D.: Trends in Arctic sea ice drift and role of wind forcing: 1992-2009, Geophys. Res. Lett., 38, L19501, doi:10.1029/2011GL048970, 2011.

Steele, M., Ermold, W., and Zhang, J.: Arctic Ocean surface warming trends over the past 100 years, Geophys. Res. Lett., 35, L02614, doi:10.1029/2007GL031651, 2008.

Stranne, C. and Björk, G.: On the Arctic Ocean ice thickness response to changes in the external forcing, Clim. Dynam., 39, 3007-3018, 2012.

Stroeve, J., Holland, M. M., Meier, W., Scambos, T., and Serreze, M.: Arctic sea ice decline: faster than forecast, Geophys. Res. Lett., 34, L09501, doi:10.1029/2007GL029703, 2007.

Stroeve, J. C., Maslanik, J., Serreze, M. C., Rigor, I., Meier, W., and Fowler, C.: Sea ice response to an extreme negative phase of the Arctic Oscillation during winter 2009/2010, Geophys. Res. Lett., 38, L02502, doi:10.1029/2010GL045662, 2011.

Stroeve, J. C., Serreze, M. C., Holland, M. M., Kay, J. E., Malanik, J., and Barrett, A. P.: The Arctic's rapidly shrinking sea ice cover: a research synthesis, Climatic Change, 110, 10051027, 2012.

Tastula, E.-M., Vihma, T., Andreas, E. L., and Galperin, B.: Validation of the diurnal cycles in atmospheric reanalyses over Antarctic sea ice, J. Geophys. Res.-Atmos., 118, 4194-4204, doi:10.1002/jgrd.50336, 2013.

Taylor, P. C., Cai, M., Hu, A., Meehl, J., Washington, W., and Zhang, G. J.: A Decomposition of Feedback Contributions to Polar Warming Amplification, J. Climate, 26, 7023-7043. doi:10.1175/JCLI-D-12-00696.1, 2013.

Thejll, P. and Lassen, K.: Solar forcing of the Northern Hemisphere land air temperature: new data, J. Atmos. Sol.-Terr. Phy., 62, 1207-1213, 2000.

Tietsche, S., Notz, D., Jungclaus, J. H., and Marotzke, J.: Recovery mechanisms of Arctic summer sea ice, Geophys. Res. Lett., 38, L02707, doi:10.1029/2010GL045698, 2011.

Tietsche, S., Day, J., Hodson, D., Keeley, S., Msadek, R., Matei, D., and Hawkins, E.: Quantifying the potential to predict Arctic climate on seasonal to interannual time scales, in: EGU General Assembly Conference Abstracts, 15, p. 11093, 2013.

Tjernström, M., Sedlar, J., and Shupe, M. D.: How well do regional climate models reproduce radiation and clouds in the Arctic?, an evaluation of ARCMIP simulations, J. Appl. Meteorol. Climatol., 47, 2405-2422, 2008.

Toole, J. M., Timmermans, M. L., Perovich, D. K., Krishfield, R. A., Proshutinsky, A., and Richter-Menge, J. A.: Influences of the ocean surface mixed layer and thermohaline stratification on Arctic Sea ice in the central Canada Basin, J. Geophys. Res.Oceans, 115, C10018, doi:10.1029/2009JC005660, 2010.

Trigo, I. F.: Climatology and interannual variability of stormtracks in the Euro-Atlantic sector: a comparison between ERA40 and NCEP/NCAR reanalyses, Clim. Dynam., 26, 127-143, doi:10.1007/s00382-005-0065-9, 2006.

Tsukernik, M., Deser, C., Alexander, M., and Tomas, R.: Atmospheric forcing of Fram Strait sea ice export: a closer look, Clim. Dynam., 35, 1349-1360, 2010.
Vavrus, S., Holland, M. M., and Bailey, D. A.: Changes in Arctic clouds during intervals of rapid sea ice loss, Clim. Dynam., 36, 1475-1489, doi:10.1007/s00382-010-0816-0, 2010.

Vihma, T., Jaagus, J., Jakobson, E., and Palo, T.: Meteorological conditions in the Arctic Ocean in spring and summer 2007 as recorded on the drifting ice station Tara, Geophys. Res. Lett., 35, L18706, doi:10.1029/2008GL034681, 2008.

Vihma, T., Tisler, P., and Uotila, P.: Atmospheric forcing on the drift of Arctic sea ice in 1989-2009, Geophys. Res. Lett., 39, L02501, doi:10.1029/2011GL050118, 2012.

Vihma, T., Pirazzini, R., Fer, I., Renfrew, I. A., Sedlar, J., Tjernström, M., Lüpkes, C., Nygård, T., Notz, D., Weiss, J., Marsan, D., Cheng, B., Birnbaum, G., Gerland, S., Chechin, D., and Gascard, J. C.: Advances in understanding and parameterization of small-scale physical processes in the marine Arctic climate system: a review, Atmos. Chem. Phys., 14, 9403-9450, doi:10.5194/acp-14-9403-2014, 2014.

Vinje, T.: Anomalies and trends of sea-ice extent and atmospheric circulation in the Nordic seas during the period 1864-1998, J. Climate, 14, 255-267, 2001.

Wadhams, P.: Diminishing sea-ice extent and thickness in the Arctic ocean, in: Environmental Security in the Arctic Ocean, Springer Netherlands, 15-30, 2013.

Wadhams, P. and Davis, N. R.: Further evidence of ice thinning in the Arctic Ocean, Geophys. Res. Lett., 27, 3973-3975, 2000.

Wallace, J. M.: North atlantic oscillatiodannular mode: two paradigms - one phenomenon, Q. J. Roy. Meteor. Soc., 126, 791805, 2000.

Walsh, J. E. and Chapman, W. L.: Arctic cloud-radiationtemperature associations in observational data and atmospheric reanalyses, J. Climate, 11, 3030-3045, doi:10.1175/15200442(1998)011<3030:ACRTAI>2.0.CO;2, 1998.

Walsh, J. E., Overland, J. E., Groisman, P. Y., and Rudolf, B.: Ongoing climate change in the Arctic, Ambio, 40, 6-16, 2011.

Wang, J., Zhang, J., Watanabe, E., Ikeda, M., Mizobata, K., Walsh, J. E., and Wu, B.: Is the dipole anomaly a major driver to record lows in Arctic summer sea ice extent?, Geophys. Res. Lett., 36, L05706, doi:10.1029/2008GL036706, 2009.

Wang, X. and Key, J. R.: Arctic surface, cloud, and radiation properties based on the AVHRR polar pathfinder dataset. Part II: Recent trends, J. Climate, 18, 2575-2593, doi:10.1175/JCLI3439.1, 2005.

Wang, Y.-H., Magnusdottir, G., Stern, H., Tian, X., and Yu, Y.: Decadal variability of the NAO: Introducing an augmented NAO index, Geophys. Res. Lett., 39, L21702, doi:10.1029/2012GL053413, 2012.

Wesslén, C., Tjernström, M., Bromwich, D. H., de Boer, G., Ekman, A. M. L., Bai, L.-S., and Wang, S.-H.: The Arctic summer atmosphere: an evaluation of reanalyses using ASCOS data, Atmos. Chem. Phys., 14, 2605-2624, doi:10.5194/acp-14-26052014, 2014.

Winton, M.: Amplified Arctic climate change: What does surface albedo feedback have to do with it? Geophys. Res. Lett., 33, L03701, doi:10.1029/2005GL025244, 2006.

Wittman, M. A., Polvani, L. M., Scott, R. K., and Charlton, A. J.: Stratospheric influence on baroclinic lifecycles and its connection to the Arctic Oscillation, Geophys. Res. Lett., 31, L16113, doi:10.1029/2004GL020503, 2004. 
Wood, K. R. and Overland, J. E.: Early 20th century Arctic warming in retrospect, Int. J. Climatol., 30, 1269-1279, 2010.

Woodgate, R. A. and Aagaard, K.: Revising the Bering Strait freshwater flux into the Arctic Ocean, Geophys. Res. Lett., 32, L02602, doi:10.1029/2004GL021747, 2005.

Woodgate, R. A., Weingartner, T., and Lindsay, R.: The 2007 Bering Strait oceanic heat flux and anomalous Arctic sea-ice retreat, Geophys. Res. Lett., 37, L01602, doi:10.1029/2009GL041621, 2010.

Woodgate, R. A., Weingartner, T. J., and Lindsay, R.: Observed increases in Bering Strait oceanic fluxes from the Pacific to the Arctic from 2001 to 2011 and their impacts on the Arctic Ocean water column, Geophys. Res. Lett., 39, L24603, doi:10.1029/2012GL054092, 2012.

Wu, B., Wang, J., and Walsh, J. E.: Dipole anomaly in the winter Arctic atmosphere and its association with sea ice motion, J. Climate, 19, 210-225, 2006.

Yang, X.-Y., Fyfe, J. C., and Flato, G. M.: The role of poleward energy transport in Arctic temperature evolution, Geophys. Res. Lett., 37, L14803, doi:10.1029/2010GL043934, 2010.

Zahn, M. and von Storch, H.: Decreased frequency of North Atlantic polar lows associated with future climate warming, Nature, 467, 309-312, 2010.

Zhang, J. and Rothrock, D. A.: Modeling global sea ice with a thickness and enthalpy distribution model in generalized curvilinear coordinates, Mon. Weather Rev., 131, 845-861, 2003.

Zhang, J., Lindsay, R., Steele, M., and Schweiger, A.: What drove the dramatic retreat of arctic sea ice during summer 2007?, Geophys. Res. Lett., 35, L11505, doi:10.1029/2008GL034005, 2008.
Zhang, J., Lindsay, R., Schweiger, A., and Steele, M.: The impact of an intense summer cyclone on 2012 Arctic sea ice retreat, Geophys. Res. Lett., 40, 720-726, doi:10.1002/grl.50190, 2013.

Zhang, X., Sorteberg, A., Zhang, J., Gerdes, R., and Comiso, J. C.: Recent radical shifts of atmospheric circulations and rapid changes in Arctic climate system, Geophys. Res. Lett., 35, L22701, doi:10.1029/2008GL035607, 2008.

Zhang, X., Ikeda, M., and Walsh, J. E.: Arctic Sea Ice and Freshwater Changes Driven by the Atmospheric Leading Mode in a Coupled Sea Ice-Ocean Model, J. Climate, 16, 2159-2177, doi:10.1175/2758.1, 2003.

Zhang, X., Walsh, J. E., Zhang, J., Bhatt, U. S., and Ikeda, M.: Climatology and interannual variability of Arctic cyclone activity: 1948-2002, J. Climate, 17, 2300-2317, 2004.

Zhang, X., He, J., Zhang, J., Polyakov, I., Gerdes, R., Inoue, J., and $\mathrm{Wu}, \mathrm{P} .:$ Enhanced poleward moisture transport and amplified northern high-latitude wetting trend, Nature Climate Change, 3, 47-51, 2012.

Zhao, Y. and Liu, A. K.: Arctic sea-ice motion and its relation to pressure field, J. Oceanogr., 63, 505-515, 2007.

Zygmuntowska, M., Rampal, P., Ivanova, N., and Smedsrud, L. H.: Uncertainties in Arctic sea ice thickness and volume: new estimates and implications for trends, The Cryosphere, 8, 705-720, doi:10.5194/tc-8-705-2014, 2014. 